\title{
Advanced Safeguards Approaches For New Fast Reactors
}
PC Durst
$\mathrm{RL}$ Wallace
I Therios MH Ehinger
$\mathrm{R}$ Bean DN Kovacic
A Dougan K Tolk
B Boyer

December 2007 
PNNL-17168

\title{
DISCLAIMER
}

This report was prepared as an account of work sponsored by an agency of the United States Government. Neither the United States Government nor any agency thereof, nor Battelle Memorial Institute, nor any of their employees, makes any warranty, express or implied, or assumes any legal liability or responsibility for the accuracy, completeness, or usefulness of any information, apparatus, product, or process diselosed, or represents that its use would not infringe privately owned rights. Reference herein to any specific commercial product, process, or service by trade name, trademark, manufacturer, or otherwise does not necessarily constitute or imply its endorsement, recommendation, or favoring by the United States Government or any agency thereof, or Battelle Memorial Institute. The views and opinions of authors expressed herein do not necessarily state or reflect those of the United States Government or any agency thereof.

\author{
PACIFIC NORTHWEST NATIONAL LABORATORY \\ operated by \\ BATTELLE \\ for the \\ UNITED STATES DEPARTMENT OF ENERGY \\ under Contract DE-AC05-76RL01830 \\ Printed in the United States of America \\ Available to DOE and DOE contractors from the \\ Office of Scientific and Technical Information, \\ P.O. Box 62, Oak Ridge, TN 37831-0062; \\ ph: (865) 576-8401 \\ fax: (865) $576-5728$ \\ email: reports@adonis.osti.gov \\ Available to the public from the National Technical Information Service, \\ U.S. Department of Commerce, 5285 Port Royal Rd., Springfield, VA 22161 \\ ph: (800) 553-6847 \\ fax: (703) 605-6900 \\ email: orders@ntis.fedworld.gov \\ online ordering: http://www.ntis.gov/ordering.htm
}

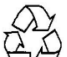

This document was printed on recycled paper

$(9 / 2003)$ 
PNNL-17168

\section{Advanced Safeguards Approaches For New Fast Reactors}

P. C. Durst, Pacific Northwest National Laboratory

I. Therios, Argonne National Laboratory

R. Bean, Idaho National Laboratory

A. Dougan, Lawrence Livermore National Laboratory

B. D. Boyer and R. Wallace, Los Alamos National Laboratory

M. Ehinger and D. Kovacic, Oak Ridge National Laboratory

K. Tolk, Sandia National Laboratory

December 2007

\section{Final Report}

Submitted Under Project - ASA-100

Advanced Safeguards Approaches

For New Fuel Cycle Facilities

Prepared for the U.S. Department of Energy under

Contract DE-AC05-76RL01830 


\section{Contents}

$\begin{array}{ll}\text { Executive Summary } & 3\end{array}$

1. Background 6

2. Description of Relevant Fast Reactors

$\begin{array}{lc}\text { 2.a Reference Facility - FBR Monju } & 8\end{array}$

2.b Historical Facility - EBR-II $\quad 10$

2.c Historical Facility - FFTF 12

2.d Advanced Burner Reactor "ABR" 13

3. The Current International Safeguards Approach for the Reference Facility 15

4. Safeguards Approach Options

4.a Traditional Monju Advanced Safeguards Approach 21

4.b Remote Monitoring 22

5. Safeguards Challenges

5.a Fresh Fuel of Varying Actinide Content 23

5.b Fully Integrated Collection and Review of Safeguards Data 23

5.c Verification of Spent TRU-Fuel 24

5.d Distributed vs. Collocated Facilities $\quad 25$

5.e Design Information Verification $\quad 26$

5.f Alternative Nuclear Materials "ANM"

5.g Equipment for Safeguards 2

6. Novel Safeguards Approaches - Longer-term Needs

6.a Process Monitoring 28

6.b Randomized Inspection Approach 28

6.c Supplementing Inspection Effort with National and Regional Inspectorates $\quad 29$

7. Conclusions and Recommendations $\quad 30$

Appendix-A:

List of Acronyms and Abbreviations $\quad 32$

$\begin{array}{ll}\text { References } & 38\end{array}$ 


\section{Executive Summary}

U.S. efforts to promote the international expansion of nuclear energy through the Global Nuclear Energy Partnership (GNEP) and other Advanced Nuclear Fuel Cycle programs could result in a dramatic expansion of nuclear fuel cycle facilities in the United States. Demonstration Facilities, such as the Advanced Fuel Cycle Facility (AFCF), the Advanced Burner Reactor (ABR), and the Consolidated Fuel Treatment Center (CFTC) will use advanced nuclear and chemical process technologies that will be more "proliferation resistant" and more amenable to the application of rigorous nuclear material safeguards.

The ASA-100 Project, "Advanced Safeguards Approaches for New Nuclear Fuel Cycle Facilities," commissioned by the NA-243 Office of NNSA, has been tasked with reviewing and developing advanced safeguards approaches for these demonstration facilities. Because a goal of these programs is developing and sharing proliferationresistant nuclear technology and services with partner nations, the safeguards approaches considered are consistent with international safeguards as currently implemented by the International Atomic Energy Agency (IAEA).

This third report in the series reviews possible safeguards approaches for new fast reactors in general, and the ABR in particular. Fast-neutron spectrum reactors have been used since the early 1960s on an experimental and developmental level, generally with fertile blanket fuels to "breed" nuclear fuel such as plutonium. Whether the reactor is designed to breed plutonium, or transmute and "burn" actinides depends mainly on the design of the reactor neutron reflector and the whether the blanket fuel is "fertile" or suitable for transmutation. However, the safeguards issues are very similar, since they pertain mainly to the receipt, shipment and storage of fresh and spent plutonium and actinide-bearing "TRU"-fuel.

For these reasons, the design of existing fast reactors and details concerning how they have been safeguarded were studied in developing advanced safeguards approaches for the new fast reactors. In this regard, the design of the Experimental Breeder Reactor-II "EBR-II" at the Idaho National Laboratory (INL) was of interest, because it was designed as a collocated fast reactor with a pyrometallurgical reprocessing and fuel fabrication line - a design option being considered for the ABR. Similarly, the design of the Fast Flux Facility (FFTF) on the Hanford Site was studied, because it was a successful prototype fast reactor that ran for two decades to evaluate fuels and the design for commercial-scale fast reactors.

In considering the advanced safeguards approaches for new fast reactors, the experiment fast breeder reactor "FBR" Monju in Japan was studied at length, because it is a very modern fast reactor currently subject to international safeguards under the IAEA. In reviewing and developing the advanced safeguards approach for the new fast reactors, the ASA-100 Project Team looked beyond the current safeguards approach used at Monju, but considered as a as a point of reference to evaluate the safeguards objectives and how they had heretofore been addressed. The team could then more easily visualize advanced 
safeguards measures that could improve safeguards effectiveness and efficiency if applied to future fast reactors.

Any safeguards approach will ultimately depend on the specific design of the facility; at this point in time only conceptual designs exist for these reactors. In looking at the new facilities in light of the historical and reference facilities, the study concluded that an effective safeguards approach for new fast reactors could be developed based on safeguards measures currently employed at the Monju fast reactor. Additionally, the team identified some opportunities to increase the efficiency of safeguards for next generation fast reactors in general and the ABR in particular. Many of these recommendations are similar to those discussed in the two previous reports in this series that address advanced safeguards approaches for new reprocessing and TRU-fuel fabrication facilities, because the TRU-fuel material being safeguarded is similar at all three plants.

These:

- Develop non-destructive assay (NDA) methods to accurately measure the plutonium $(\mathrm{Pu})$ and actinide content in fresh and spent TRU-fuel assemblies being received and shipped from the fast reactor. (This is currently complicated by the presence of other "minor actinides" and the high neutron and gamma radiation field of the spent fuel. These methods should be capable of detecting "partial defects" in accordance with current IAEA criteria, i.e., having an accuracy of approximately $+/-5 \%$ total $\mathrm{Pu}$ and other actinides.) To demonstrate these methods, samples of the TRU materials planned for the future facilities, and a simulation of the background in which they will be measured, will have to be prepared for testing purposes.

- Many of these NDA methods or systems will need to be designed "in-line" to measure the fresh fuel transfers to fuel storage and to the reactor core, and spent fuel transfers to spent fuel storage and from the reactor. These methods should be amenable to remote data transmission to permit "remote monitoring" of the facility for more efficient safeguards. Many of the NDA techniques are dependent on the geometry of the TRU-fuel and/or container. So, once the assay techniques are selected, the assay stations for the fresh and spent fuel will need to be "mockedup" to prove the techniques.

- Make greater use of automated, unattended/remote monitoring systems for collecting safeguards data, while cooperating with the facility owner/operator and national authorities to ensure protection of proprietary information. And develop a more completely automated and integrated safeguards data collect and review system for analyzing process and on-line assay data and surveillance imagery to support verification of the nuclear material transfers, inventory, and operational status of the facility. 
- Establish an active dialogue with the IAEA to negotiate a more flexible interpretation of the IAEA Department of Safeguards SGTS Policy \#20, concerning the joint use of equipment for safeguards purposes. Because of the need to derive independent safeguards conclusions from instrumentation, current interpretations of Policy \#20 are restrictive and limit the ability of the IAEA to use a broad range of existing plant instruments. It is proposed that this strict interpretation should be applied only to those instruments of primary safeguards importance - and not to the extensive array of plant instruments which could still provide complementary data of safeguards relevance with regard to operation of the facility.

- Cooperate with the facility owner/operator and national authorities to try to design safeguards requirements and equipment into the conceptual design at the earliest stages of the conceptual design of the facility.

- Use randomized short-notice inspections, applying a "statistical process control" approach to verification of the nuclear material in the fast reactor rather than a scheduled systematic verification of all major transfers of plutonium-bearing materials. (For this kind of approach to be effective the facility operator would need to declare the major activities involving nuclear material in advance. It would also be more efficient and effective to apply this approach on a site, rather than facility level.)

- Current safeguards approaches for fast reactors depend strongly on the storage areas and transfer paths of the fresh and spent TRU-fuel. There is a need to review the current conceptual designs to see that secure storage areas are designed into the process to facilitate stable process flows and to provide locations that will facilitate inventorying the nuclear material.

These opportunities must be addressed in order to move the application of international safeguards at fast reactors to a higher level of efficiency and effectiveness. 


\section{Background}

As the United States works to promote the global expansion of nuclear power through its Global Nuclear Energy Partnership (GNEP) and other Advanced Nuclear Fuel Cycle programs, the nuclear fuel cycle in the United States is expected to expand substantially. New facilities will be constructed employing advanced nuclear and chemical process technologies. In addition, it is envisioned that these new Demonstration Facilities will be designed to be inherently easier to safeguard and more proliferation-resistant. Two of the main objectives of these programs are the recycle of nuclear fuel using new technologies to recover more energy and minimize long-term radioactive waste, and to reduce proliferation risks through the use of these new "proliferation resistant" technologies. ${ }^{1}$ The facilities that will demonstrate this new proliferation-resistant nuclear fuel-cycle include the Advanced Fuel Cycle Facility (AFCF), the Advanced Burner Reactor (ABR), and the Consolidated Fuel Treatment Center (CFTC, formerly called ESD). ${ }^{2}$

The ASA-100 Project, "Advanced Safeguards Approaches for New Nuclear Fuel Cycle Facilities," commissioned by the NA-243 Office of NNSA, has been tasked with reviewing and developing advanced safeguards approaches for these Demonstration Facilities. The United States has consistently demonstrated its support for international safeguards, as evidenced by the US government having over 280 nuclear facilities listed on the Eligible Facility List (EFL) under its Voluntary Offer (Safeguards) Agreement with the IAEA. It is likely that these Demonstration Facilities would be placed on this list as well. Furthermore, the development and sharing of proliferation-resistant nuclear technology and services is a GNEP and Advanced Nuclear Fuel Cycle cornerstone. Therefore, the conceptual safeguards approaches developed in this study are consistent with international (IAEA) safeguards and practices.

This third report in the series reviews possible safeguards approaches for new fast reactors in general, and the ABR in particular. Fast-neutron spectrum reactors have been used since the early 1960s on an experimental and developmental level, generally with fertile blanket fuels to "breed" nuclear fuel such as plutonium. Whether the reactor is designed to breed plutonium, or transmute and "burn" actinides depends mainly on the design of the reactor neutron reflector and the whether the blanket fuel is "fertile" or suitable for transmutation. However, the safeguards issues are very similar, since they pertain mainly to the receipt, shipment and storage of fresh and spent plutonium and actinide-bearing "TRU"-fuel.

For these reasons, the design of existing fast reactors and details concerning how they have been safeguarded were studied in developing advanced safeguards approaches for the new fast reactors. In this regard, the design of the Experimental Breeder Reactor-II "EBR-II" at the Idaho National Laboratory (INL) was of interest, because it was designed as a collocated fast reactor with a pyrometallurgical reprocessing and fuel fabrication line - a design option being considered for the ABR. Similarly, the design of the Fast Flux Facility (FFTF) on the Hanford Site was studied, because it was a successful prototype fast reactor that ran for two decades to evaluate fuels and the design for commercial-scale fast reactors. 
In considering the advanced safeguards approaches for new fast reactors, the experimental fast breeder reactor "FBR" Monju in Japan was studied at length, because it is a very modern fast reactor currently subject to international safeguards under the IAEA. The team used the approach at Monju as a point of reference to evaluate the safeguards objectives and how they had heretofore been addressed, while envisioning advanced safeguards measures that could improve safeguards effectiveness and efficiency if applied to future fast reactors.

The safeguards objective addressed by the approaches presented in this report is consistent with the goals of the IAEA; specifically, the timely detection of the diversion of one significant quantity (SQ) of nuclear material. ${ }^{3}$ The over-arching objective is the detection of the diversion of 8 kilograms of plutonium within one month of diversion. It should be understood from this study that safeguards measures also apply to uranium (although to a lesser extent) and may also be applied to alternative nuclear materials (ANM) in the future, such as neptunium and americium.

Traditionally, safeguards have depended primarily on nuclear material accountancy (e.g. accountability), supplemented with containment and surveillance. It is well recognized that safeguards objectives in a facility with a large nuclear material throughput cannot be met by nuclear material accountancy alone. To address this weakness, the conceptual approaches considered in this report introduce other safeguards measures in addition to accountancy that, in combination, will allow the inspecting authority to meet the safeguards objective. 


\section{Description of Relevant Fast Reactors}

\section{2.a Reference Facility - FBR Monju ${ }^{4,5}$}

Monju is a prototype fast breeder reactor, built and constructed in Japan near the city of Tsuruga on the west coast of the Japanese main island of Honshu. Because it was intended to allow Japan to make more efficient use of nuclear fuel by permitting the "breeding" and recycling of plutonium, it was named after the Buddhist deity of wisdom called "Manjusri" in Sanskrit and "Monju" in Japanese. Monju is rated at 714 MWth output and $280 \mathrm{MWe}$ and is owned and operated currently by the Japan Atomic Energy Agency (JAEA), formerly also called PNC and JNC. Monju went critical and began operation in 1994, but shortly afterwards a sodium leak developed, which resulted in a fire affecting the sodium coolant loop. The reactor was safely shutdown and the damaged parts of the reactor sodium cooling loop have been refurbished, but restart of the facility remains uncertain and dependent on regional politics in Tsuruga Prefecture and Japanese national energy policies. Meanwhile, the facility still contains fresh TRUfuel, TRU-fuel assemblies in the reactor core and spent TRU fuel assemblies, which are and have been subject to monthly safeguards inspection by the IAEA since receipt of TRU-fuel since circa 1994. Because Monju is a relatively large-scale and modern fast reactor and because a very advanced international safeguards approach has been applied to Monju, it is a suitable point of reference for developing advanced safeguards approaches for other new fast reactors, including the ABR. A photograph of Monju is shown in Figure-2-1 and a simplified process flow schematic showing the primary existing safeguards measures is shown in Figure-2-2.

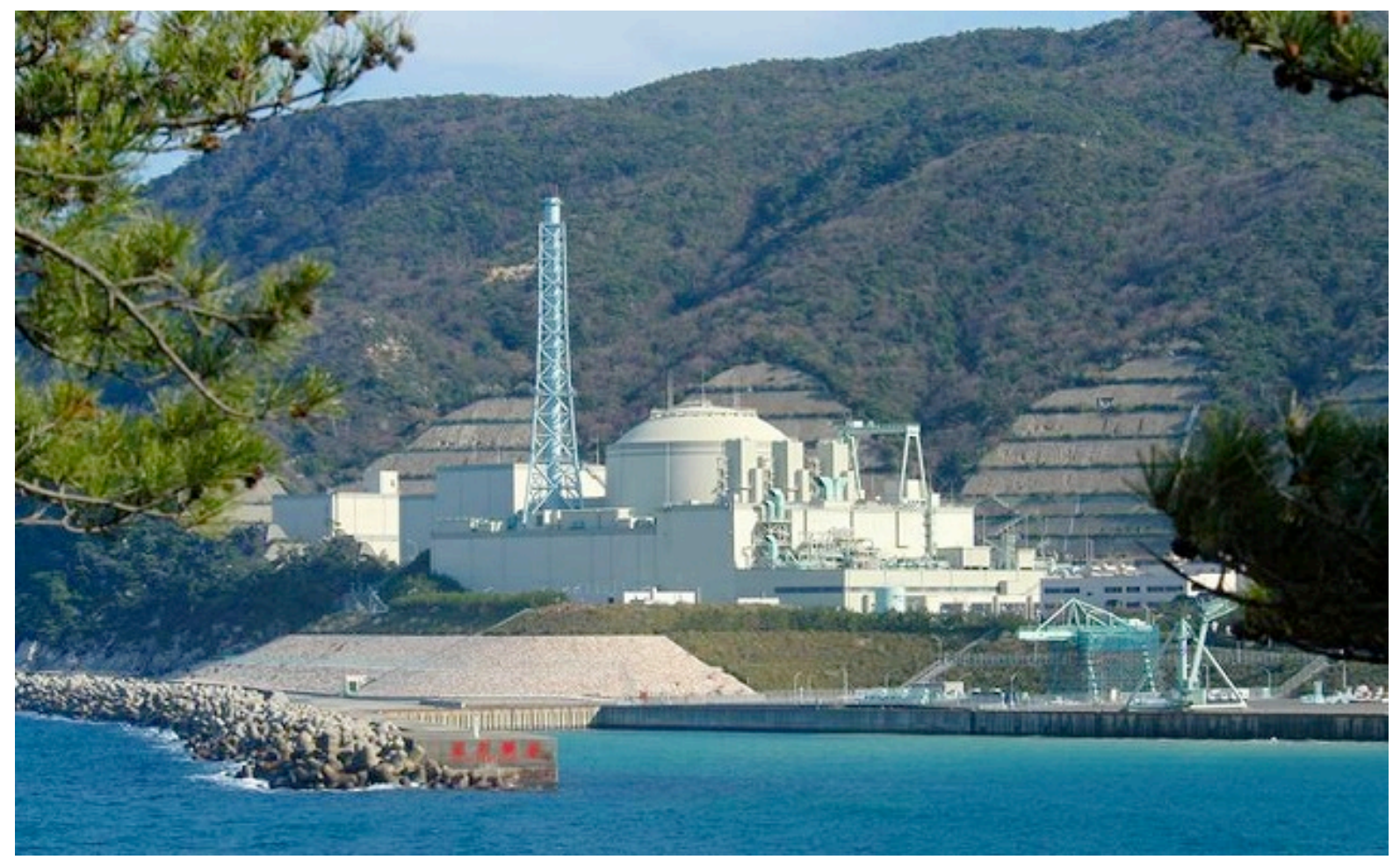

Figure 2-1: Photograph of Monju (Japan) 


\section{Figure 2-2: Simplified Process Schematic of Nuclear Fuel Flow at Monju}

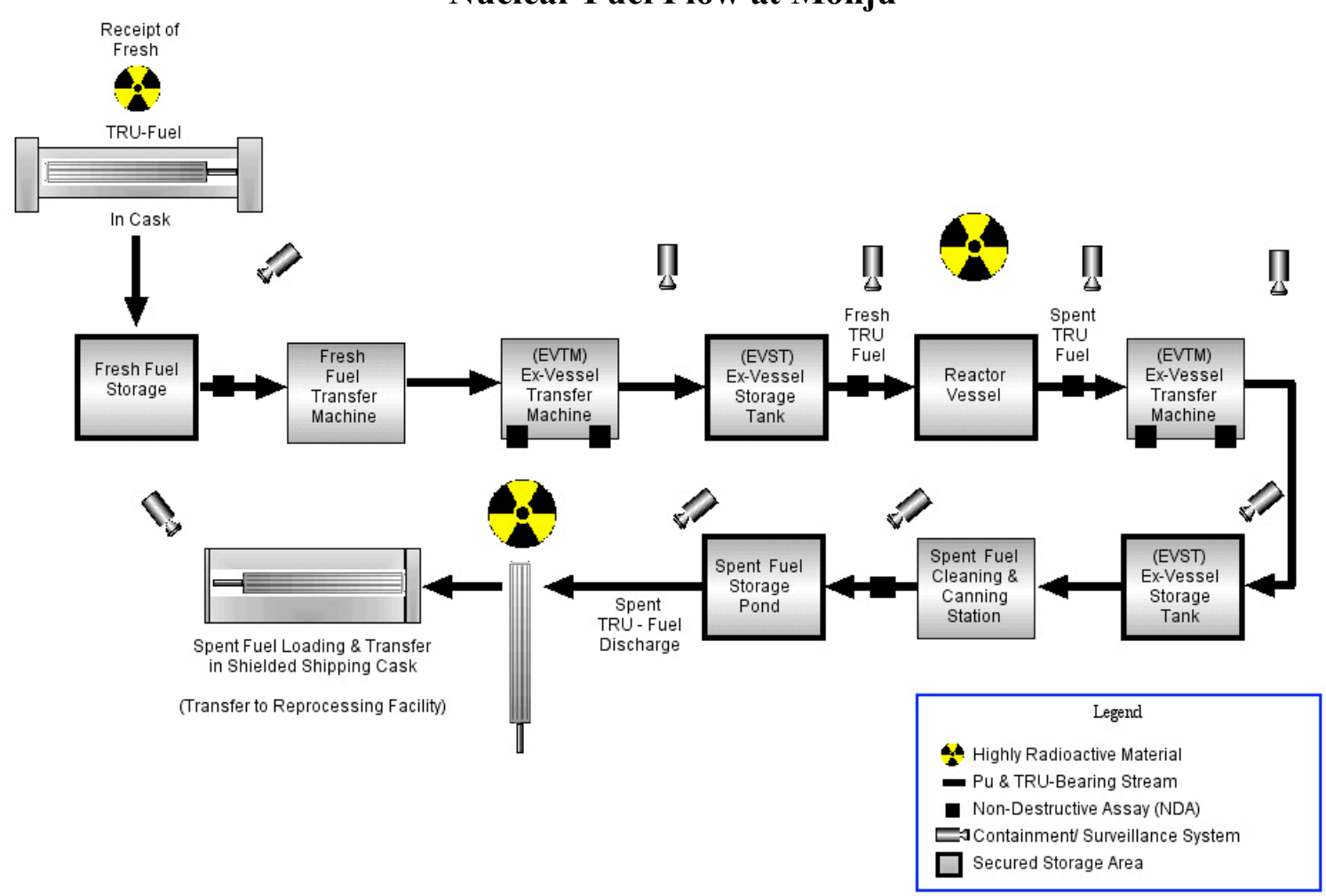

Monju uses 198 plutonium-uranium mixed oxide "MOX", or "TRU"-assemblies in the reactor core and 172 depleted-uranium "DU" assemblies as the fertile fuel in the blanket region of the core. The reactor was designed to produce a fast-neutron spectrum from the fission of plutonium that would not only generate great amounts of energy for electrical production, but would also cause the DU in the blanket fuel to "breed" and convert to $\mathrm{Pu}$ 239 through successive neutron capture. In Monju, since the TRU-fuel contains plutonium, the storage and transfers of fresh and spent nuclear fuel are subject to rigorous nuclear material safeguards and regular inspection. In this regard, the areas of greatest interest in terms of safeguards include the TRU-fuel stored in the Fresh Fuel Store, the Reactor Vessel (or core), the Ex-Vessel Storage "EVST" (an intermediate holding area for fuel outside of the Reactor Vessel), and the Spent Fuel Pond. Specially designed fuel transfer carts traverse fixed fuel transfer pathways to convey fresh fuel from the Fresh Fuel Store to the EVST and from the EVST to the Reactor Vessel. Similarly, spent TRUfuel is conveyed from the Reactor Vessel to the EVST and to the Spent Fuel Storage Pond. The fuel transfer paths and storage areas are monitored by redundant video surveillance, with the fresh fuel being under additional containment (redundant sealing). Unattended radiation monitors are used to detect flow of TRU-fuel from the Fresh Fuel Store, the loading of TRU-fuel on the fuel transfer cart and transfers to, or from the EVST and Reactor Vessel. More will be said about the specific international safeguards approach applied to Monju in Section-3. Fundamentally, the approach is based on rigorously monitoring TRU-fuel storage and transfers with redundant containment, surveillance, and specially designed radiation monitors. Fuel receipts or shipments from 
the facility are similarly monitored by redundant video surveillance systems. These systems are down-loaded by IAEA inspectors monthly to permit a timely evaluation of the safeguards data.

For this study, Monju is an important point of reference, because a very sophisticated international safeguards approach has been developed using advanced safeguards measures to monitor the storage and transfer of plutonium-bearing fuel. This approach is also amenable to "remote monitoring" - a concept that will be discussed in more detail in Section-3 and in Section-7, "Novel Safeguards Approaches". Monju is also a relatively large reactor, more akin to a demonstration prototype advanced fast reactor, such as the ABR.

\section{2.b Historical Facility - EBR-II}

The Experimental Breeder Reactor-II "EBR-II" was a relatively small, but complete reactor complex designed by the Argonne National Laboratory and operated on the Idaho National Laboratory "INL" Site in the mid 1960s through the 1980s. The reactor had a 62.5 MWth and a 20 MWe power output. In comparison to the 714 MWth design output of Monju it is clear that it is a much smaller fast reactor. However, EBR-II was not merely a test reactor, but was complete with an electric power generation plant, and more relevant to this discussion, a complete collocated pyrometallurgical reprocessing and fuel fabrication line. A site diagram of the EBR-II Facility and ancillary structures as they were in the 1960s appears in Figure 2-3.

Figure 2-3:

\section{Site Diagram of EBR-II and Collocated Fuel-Cycle Facility (Idaho, USA) ${ }^{6}$}

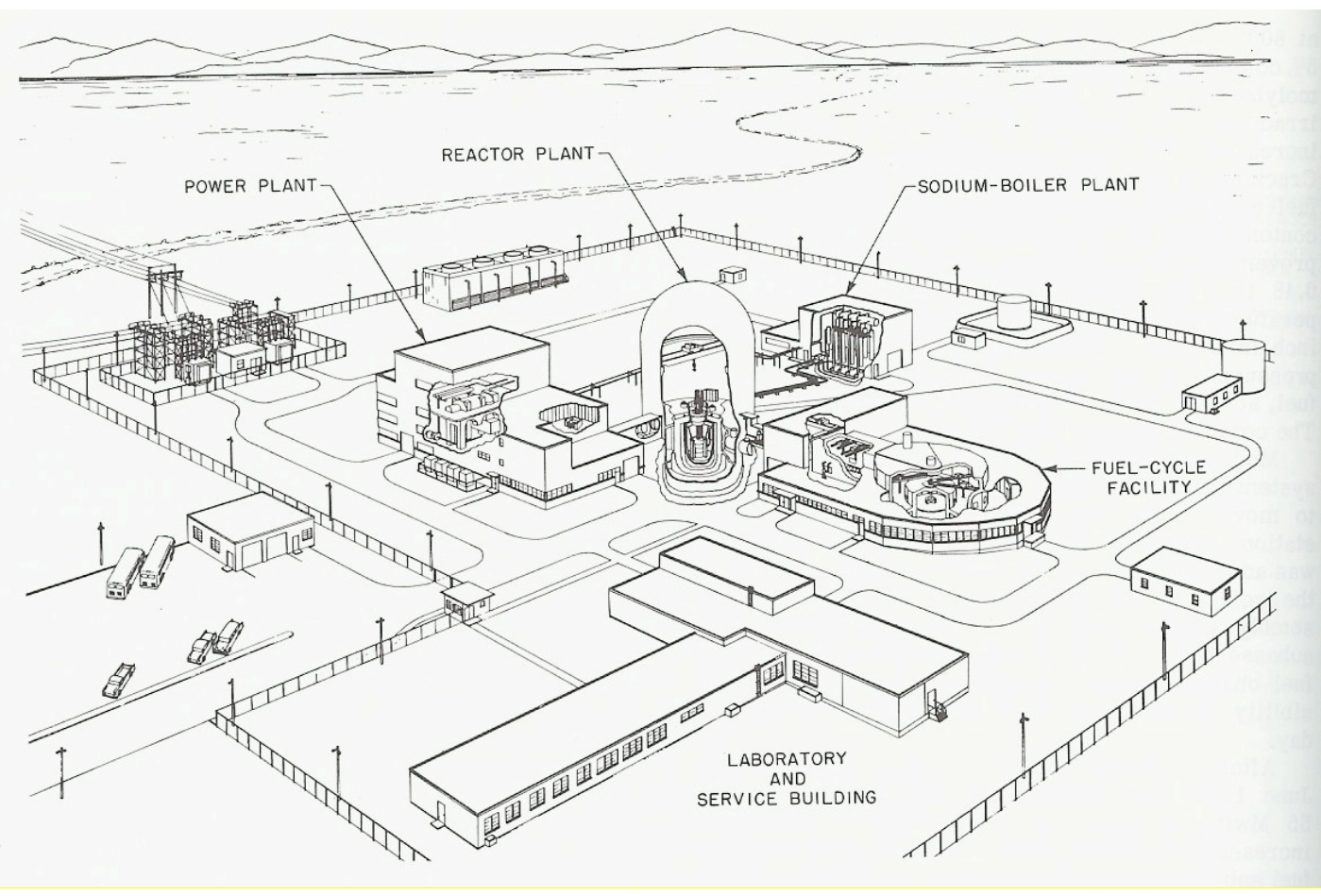


The purpose of EBR-II was not only to demonstrate that a breeder reactor could be safely operated to generate electricity, but that it was possible to remove the spent fuel from the breeder reactor, remove the neutron-poisoning fission products from the fuel through pyroprocessing, recast the recycled nuclear material into fresh fuel pins, and recharge the recycled fuel to the reactor. This process was referred to as the Integrated Fuel Cycle which combined power generation, fuel reprocessing, and fuel fabrication on one site. This was probably one of the first, if not the first, demonstration of this concept involving a power-generating nuclear power plant. This also became the model for subsequent grander schemes, including concepts proposed for the ABR, as well as by Toshiba Ltd. of Japan, who put forward a conceptual design and model of a block of commercial fast reactors collocated with an integrated fuel cycle center. ${ }^{7}$ The main appeal of the collocated integrated fuel cycle facility is that the shipment and receipt of nuclear fuel from the facility would be dramatically reduced compared to the typical light water reactors in operation. Because there is no off-site shipment of fresh fuel or spent fuel, the physical protection vulnerabilities associated with transportation legs are avoided. The physical protection of the integrated site itself would be based on a detailed security vulnerability assessment that takes into account the relative accessibility of "targets" and the effectiveness of design features and the physical protection system in mitigating the identified vulnerabilities. This again is one of the main reasons why the idea of collocation is being considered for the conceptual design of the ABR. This topic will be discussed in more detail in Section 5-6. EBR-II was a relatively small breeder reactor and as such, consumed small amounts of nuclear fuel; larger commercial-sized facilities would require larger fresh and spent nuclear fuel storage areas to ensure that adequate fuel is on-hand for nearly continuous operation. The relevant engineering specifications of EBR-II are as noted in Table 2-1 below.

\section{Table 2-1: Engineering Specifications for EBR-II ${ }^{8}$}

\begin{tabular}{|l|l|}
\hline Power Output - Thermal & $62.5 \mathrm{MWth}$ \\
\hline Power Output - Electrical & $20 \mathrm{MWe}$ \\
\hline Reactor Type & Fast Breeder Reactor \\
\hline $\begin{array}{l}\text { Coolant } \\
\text { Primary and Secondary Loops }\end{array}$ & Liquid Metal - Sodium \\
\hline $\begin{array}{l}\text { Reactor Inlet Temp. } \\
\text { (Primary Sodium Loop) }\end{array}$ & 370 Deg. C \\
\hline $\begin{array}{l}\text { Reactor Outlet Temp. } \\
\text { (Primary Sodium Loop) }\end{array}$ & 480 Deg. C \\
\hline Reactor Core Diameter & $0.483 \mathrm{~m}$ \\
\hline Reactor Core Height & $0.361 \mathrm{~m}$ \\
\hline Driver Fuel & Highly Enriched Uranium (49\% U-235) $170 \mathrm{~kg}(\mathrm{U}-235)$ \\
\hline Blanket Fuel & Depleted Uranium $(<0.7 \%$ U-235) 28,100 kg (Uranium) \\
\hline
\end{tabular}

The EBR-II facility was never subject to international (IAEA) safeguards. However, it was subject to rigorous nuclear material safeguards under the U.S. Atomic Energy Commission "AEC", Energy Research and Development Administration "ERDA", and 
ultimately the Department of Energy "DOE". Consequently, the facility was subject to domestic safeguards requirements and inspections. The primary means of accounting for the nuclear material was accounting for the number of fuel assemblies in the reactor core, the fresh fuel store or spent fuel storage area. The plutonium and uranium content of nuclear material in the pyrometallurgical process was estimated using fuel burn-up codes, such as ORIGIN, based on the weight of the material, initial composition and irradiation history. The relatively small amounts of nuclear material made it easier to safeguard and account for the material, although accounting for the nuclear material in the reprocessing and fabrication steps was necessarily more challenging due to the loss of material to solid TRU-waste streams.

\section{2.c Historical Facility - FFTF ${ }^{9}$}

The Fast Flux Test Facility is a 400 MWth liquid metal-cooled fast reactor on the U.S. DOE Hanford Site that was completed in 1978 and tested new fast reactor fuels and materials from 1980 to 1992 . The facility has been partially decommissioned. The facility is on the order of the size of the reference fast reactor, Monju (714 MWth) and is at the lower end of the size range being considered for the Advanced Burner Reactor "ABR" (500 to 2,000 MWth). Consequently, it is relevant when considering the conceptual design of the ABR. It also had a successful operating period of over 10 years as a test bed for qualifying new nuclear fuels and materials in a "fast-flux" neutron environment. So, experience with the reactor design, controls, instrumentation, fuel and sodium coolant systems is relevant and valuable. The FFTF is shown in Figure-2-4.

Figure 2-4:

Fast Flux Test Facility (Hanford DOE Site, USA) ${ }^{10}$

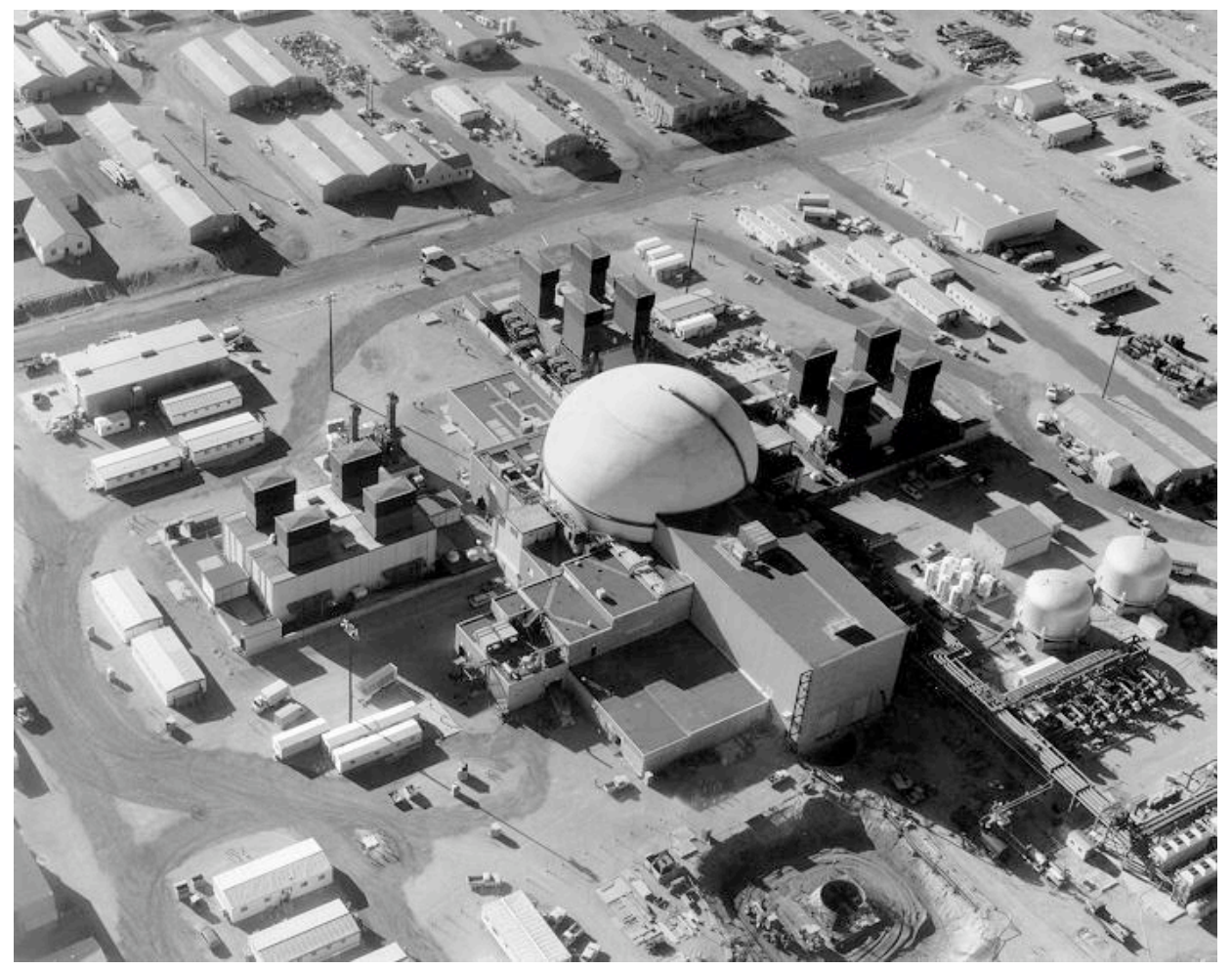


The main engineering features of the facility are as follows. The fast reactor is rated at 400 MWth power output. FFTF has no electric power rating, because the facility was used to test fuels and materials - consequently, since reactor operation would necessarily be intermittent, it was not designed with a turbine-generator for the production of electricity. For this reason, there are 12 large air-cooled monolith-shaped heat exchangers built around the reactor to dissipate heat removed from the reactor core during operation.

The reactor contained up to 91 fuel assemblies, consisting of 75 driver TRU-assemblies containing 20 to $30 \% \mathrm{Pu}$. The balance was blanket assemblies of depleted uranium. Fresh driver and blanket fuel was stored in the secured fresh fuel storage area. Spent fuel was removed from the reactor core using a custom-designed refueling and fuel transfer machine, was cleaned of liquid sodium and was stored in the spent fuel pond.

Regarding the application of safeguards at FFTF, it was subject to rigorous domestic safeguards and security regulations as applied by U.S. DOE. The facility had been placed on the United States Eligible Facility List (EFL) under the U.S. Voluntary Offer Safeguards Agreement with the IAEA, although the facility was not frequently selected by the IAEA for safeguards inspection. The safeguards measures that had been applied to the nuclear material at the facility were similar to those that had been applied to light water reactors (LWRs) in the 1980s. These measures included; systematic maintenance of nuclear material accounting records, filing of inventory change and material balance reports to the U.S. national authorities (DOE), item counting and identification of a statistical random sample of fresh fuel, core fuel and spent fuel, typically during the annual physical inventory taking (PIT). The U-235 and Pu content of the fresh fuel was determined using an active well coincident counter (AWCC) and the spent fuel was verified qualitatively as having the "attribute of radioactive spent fuel" by verification of the Cerenkov glow. Nuclear material content in the spent fuel was estimated based on the use of spent fuel burn-up software codes, such as ORIGEN, which had been optimized for fast reactor fuel at FFTF. Safeguards of the nuclear material at the reactor were based primarily on accounting for the nuclear fuel as "integral items" and confirming that none of the "items" were missing. However, the AWCC was used to verify and account for the U-235 and Pu content in the fresh fuel. In addition to the accounting and nuclear material verification safeguards measures, containment/surveillance measures were used for monitoring the material and as part of the physical protection system for the plant.

\section{2.d Advanced Burner Reactor (ABR) ${ }^{11}$}

The Advanced Burner Reactor "ABR" is a conceptual fast reactor, being considered to transmute or "burn" long-lived actinides, which will be incorporated into specially created transuranic "TRU" fuel. The preliminary specifications as described in the U.S. DOE Request for Expression of Interest are similar in concept to FFTF and Monju. The conceptual features of the ABR as currently specified are a 500 to 2,000 MWth liquidmetal (sodium) cooled fast reactor, with an electrical power output of 200 to $800 \mathrm{MWe}$. The thermodynamic cycle is expected to be a conventional Rankine-steam or Brayton carbon-dioxide cycle. The reactor fuel will be either U/TRU-oxide or metal. The TRU 
content of the fresh fuel will be primarily plutonium, typically on the average of $25 \%$ of heavy metal. However, since the reactor will be designed to transmute actinides it is also expected to have elevated contents of neptunium, americium, and curium in the fuel. The ABR will have the ability to start on conventional TRU or HEU fast reactor driver fuel. It is also expected to be able to operate on a full core of transmutation fuel and will have the capability to transmute "minor actinide" targets prior to this transition. "Sufficient process storage capacity for spent fuel" is specified, although only in general terms. Based on typical reactor construction to date, this would be on the order of 10 years of spent fuel storage capacity. The specifications do indicate the possibility that the ABR may be collocated with the TRU fuel reprocessing and fuel fabrication facilities, such as at EBR-II, as previously noted. However, this is not a binding requirement. The primary focus of the Request for Expression of Interest appears to be in generating the interest of commercial nuclear power plant designer/constructors that could provide a prototype commercial fast reactor to perform the TRU-transmutation function noted.

Because the ABR as specified is comparable in size to FFTF and Monju, it is expected that an advanced safeguards approach would be similar to the safeguards approach currently applied by the IAEA to Monju, which will be discussed in Section-3. However, this report also addresses new ideas and novel approaches, which should be considered for the sake of improving the effectiveness and efficiency of an advanced safeguard approach for future fast reactors. 


\section{The Current International Safeguards Approach for the Reference Facility}

The safeguards approach for Monju was developed in the context of an INFCIRC/153type comprehensive safeguards agreement concluded between Japan and the IAEA. The international safeguards objective is the timely detection of the possible diversion of the plutonium-bearing TRU-fuel at Monju. The goal quantity for detection is $1 \mathrm{SQ}$ (or $8 \mathrm{~kg}$ of $\mathrm{Pu}$ ) in the form of TRU-fuel, fuel rods, or portions thereof. ${ }^{12}$ Safeguards also apply to uranium, but to a lesser extent. The timeliness goal for detecting the possible diversion depends on whether the plutonium is in un-irradiated "fresh" or irradiated "spent" fuel. In the former case, the timeliness goal is one month. In the latter case, the timeliness goal is three months. ${ }^{1}$ The former essentially dictates the need for monthly field inspections by the IAEA inspectors. Possible variations from this strict safeguards criteria will be discussed in Section-7, "Novel Safeguards Approaches - Possibilities".

The safeguards approach for Monju is based on the traditional approach applied to all MOX or TRU-fuel Reactors in accordance with the IAEA safeguards agreement, which includes: ${ }^{13}$

- Defined Material Balance Areas (MBA) for nuclear material accounting

- Defined Key Measurement Points (KMPs) for measuring the flow and inventory of nuclear material

- Defined Strategic Points for containment and surveillance $(\mathrm{C} / \mathrm{S})$ and other verification measures

- Nuclear Material Accountancy, via review of operating records and state reports

- Annual Physical Inventory Verification (PIV) - typically a "shutdown" inventory taking during semi-annual fuel reloading

- Verification of domestic and international transfers of nuclear material

- Statistical evaluation of the nuclear material balance to determine "Material Unaccounted for" (MUF)

- Routine, (monthly) interim inventory verifications (IIVs) for the timely detection of possible diversion of nuclear material

- Verification of facility design information

- Verification of the operator's measurement system

In addition to the safeguards measures and features noted above, additional features were provided at Monju to ensure robust safeguarding of the TRU-fuel, including:

- Hardened secured storage locations for the TRU-fuel assemblies.

- Advanced redundant containment and surveillance systems, consisting of several kinds of sensors, gamma-detectors, neutron detectors, and surveillance cameras. The digital data from these systems are reviewed by a super-fast image processing review system to detect changes in the areas under surveillance, in a semiautomated manner.

- Continuous, unattended custom-designed non-destructive assay "NDA" systems to monitor the movement of TRU fuel in the facility and to determine by

\footnotetext{
${ }^{1}$ This may be changing for States under Integrated Safeguards.
} 
interpreting the gamma and neutron radiation if the fuel is a non-fuel dummy, fresh TRU-fuel, DU blanket fuel, or spent TRU fuel.

- Monju was designed with safeguards in mind, being perhaps the first fast reactor in the world in which the "Safeguards by Design" concept was implemented.

In addition to those specific safeguards verification activities at Monju and the frequency of verification and probability of detection as described in the relevant IAEA Safeguards Criteria, the following were specified: ${ }^{14,15}$

- Early provision of facility design information by the national authorities (at the time the decision is made by the national authorities to construct or modify a nuclear facility),

- The use of environmental sampling by the IAEA to detect traces of radioactive contamination to verify the facility operator's declared use (and former use) of the facility.

Additional measures are also employed at Monju as allowed under the Additional Protocol to the Safeguard agreement between Japan and the IAEA. ${ }^{16}$ This Additional Protocol "AP" provides for the following:

- Provision of additional information by Japan, declaring all nuclear facilities and activities in the country, which is annually updated,

- Annual provision by Japan of information regarding the manufacturing of nuclear-related equipment (such as reactor vessels), and nuclear-related research (such as fast-reactor related research),

- The right for the IAEA to conduct Complementary Access "CA" at nuclear sites and areas of suspected nuclear research at short notice to detect undeclared nuclear material and/or activities,

- The right of the IAEA to use visual observation, collection of environmental samples, and radiation detection devices to detect undeclared nuclear material and/or activity.

Because the TRU-fuel at Monju is the focus of safeguards, the primary areas of safeguards interest are the secured storage areas for the fuel and the transfer paths for the fuel into and out of the reactor. Figure 2-2 is a simplified schematic that shows the flow of fresh fuel and spent fuel in the reactor. A layout diagram of the Monju reactor showing the primary surveillance and non-destructive assay "NDA" stations is shown in Figure 3-1. A short description of the fuel handling and relevant safeguards measures is as follows: Fresh fuel is received in a sealed fresh fuel cask and is unloaded under redundant surveillance into the fresh fuel storage pits. The plutonium-content of the fresh TRU-fuel in this case was most likely previously verified at the TRU fuel fabrication plant (in this case, PFPF in Japan). The fresh TRU fuel is unloaded under the presence of inspectors and is stored in the fresh fuel storage pits under redundant seals (VACOSS electronic and metal cap seals). For reloading the core, fresh fuel would be unsealed under redundant video surveillance and transferred through an NDA station, the Entrance Gate Monitor "ENGM". The measurement resolution of the existing NDA stations at Monju cannot determine accurately the plutonium content of the fresh or spent fuel. Rather, they are used to item count the number of assemblies transferred and to verify the 
facility operator's declaration qualitatively - i.e. confirm if the TRU fuel assembly is a "non-fuel" dummy, fresh TRU-fuel, DU blanket fuel, or highly radioactive spent TRUfuel.

In this regard, the safeguards approach at Monju, like most reactors, is based on detecting the removal of integral fuel "items". The fresh fuel assembly is transferred by an underfloor transporter and is uplifted into one of the transport wells of the Ex-Vessel Transfer Machine "EVTM", which shuttles the fresh TRU-fuel to the Ex-Vessel Storage Tank "EVST". The presence of the fuel and the type of fuel is determined by the neutron and gamma radiation as detected by the Ex-Vessel Radiation Monitors "EVRM", which sit adjacent to the two fuel transfer wells of the EVTM transfer machine. Additional ExVessel Storage Tank "EVST" monitors also confirm that TRU fuel is being transferred in or out of the EVST storage tank. The fresh TRU fuel is stored in liquid sodium in the EVST storage tank and is transferred to the reactor vessel during fuel the fuel reloading activity. Normally the core reloading would have taken place semi-annually, but Monju has been shutdown in a state of readiness for restarting since the sodium coolant leak and fire in 1995. Although, the reactor at Monju has not operated since 1995, the facility is still subject to monthly inspections by the IAEA. The fuel assay and safeguards surveillance data continues to be collected in unattended mode and down-loaded monthly for safeguards review and evaluation. A Core Reactor Power Monitor "RPM" sits adjacent to the reactor refueling port for the ex-vessel transfer machine and will detect the insertion and removal of fresh or spent TRU fuel into the reactor vessel.

The transfer of spent fuel from the reactor vessel follows a similar path, although in reverse: Spent fuel is picked up by the ex-vessel transfer machine and shuttled to the exvessel storage tank. As in the case of fresh fuel, the RPM, EVRM, and EVST radiation monitors will detect the fuel movement. From the relative gamma and neutron radiation detected, the type of fuel can be determined. After interim holding and cooling in the exvessel storage tank, the spent fuel is shuttled by the ex-vessel transfer machine to the storage wells of the spent fuel cleaning and canning station for removal of any sodium on the spent fuel assembly. The spent fuel passes through an Exit Gate Monitor "EXGM" and is transferred through an underwater channel for storage in the spent fuel storage pond, which is under redundant surveillance. It is true that during transfer to and from the reactor, the TRU fuel is not visible, although the fuel movement is deduced from the radiation emissions and characteristic movement of the ex-vessel transfer machine. During the monthly safeguards evaluation, special care is taken to correlate the timing and intensity of the neutron and gamma radiation spikes detected to confirm that the movement of the TRU fuel, blanket and even dummy assemblies were as declared by the facility operator. Additionally, all major transfer routes and access pathways to the TRU fuel are in the field of view of the redundant video surveillance cameras to detect possible undeclared removal of TRU fuel from the facility. 
Figure 3-1:

Simplified Facility Layout Diagram of Monju

Showing Primary Safeguards Equipment

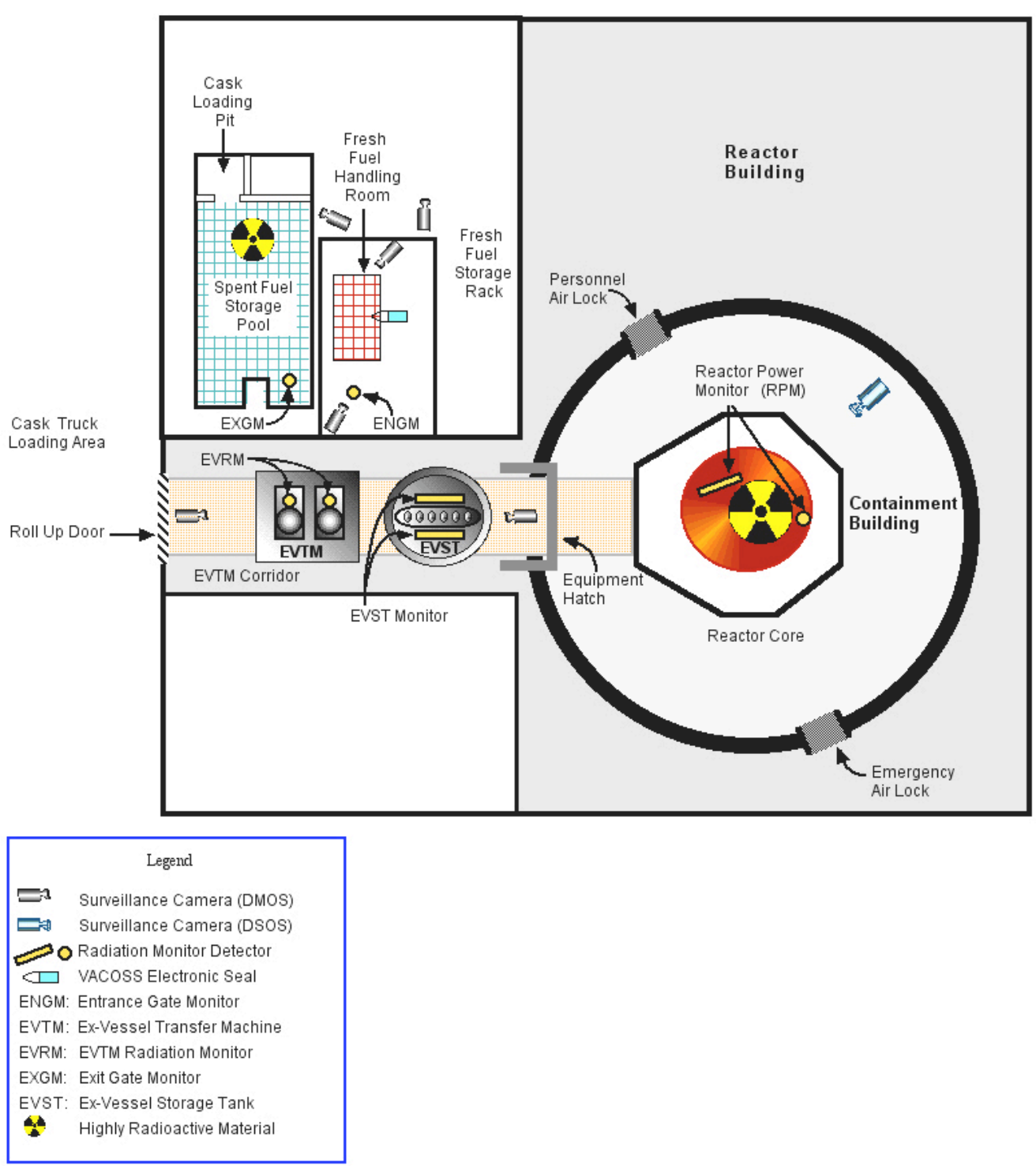

A summary list of the custom designed NDA and surveillance systems developed for Monju is shown in Table 3-1.

Despite the considerable evolution and development of unattended installed safeguards NDA and surveillance systems at Monju, there are still significant challenges, which would most likely be similar to challenges in safeguarding new fast reactors, such as the ABR. At Monju, these challenges can be summarized: ${ }^{2,18}$

\footnotetext{
${ }^{2}$ The issues noted are in the process of being addressed by tasks as per the current U.S. DOE and JAEA bilateral cooperation agreement regarding nuclear material safeguards.
} 
- Data from the unattended radiation monitors is downloaded from individual "data collect" stations. This data is then reviewed individually. Correlation between the responses from other radiation monitors must be done separately and in an ad hoc manner. It is desirable for the NDA and surveillance data to be reviewed on a common review platform and in a more automated and integrated manner. The current method requires far too much inspector direction and intervention.

- In 2005, the NDA and surveillance data at Monju was being downloaded at individual "data collect" stations, although the safeguards of the facility could have been more effectively monitored if the data were collected centrally. This arrangement would also have been more amenable to "remote monitoring" of the facility - which in the future could allow safeguards inspectors the ability to monitor the facility remotely, and which would necessarily reduce the number of inspections at the facility. ${ }^{3,19}$

- Common-mode failure paths still exist, even though most of the NDA and surveillance systems at Monju are installed with redundancy. This is particularly evident in the process of manually downloading the NDA and surveillance imagery data onto disk or storage tape and installing fresh storage media, i.e. potentially installing "write-protected" media for the next inspection period. These commonmode failure pathways should be eliminated.

- The Entrance Gate Monitor "ENGM" is effectively a passive coincident neutron well counter designed to verify the Pu content in fresh TRU (MOX) fuel to a level of detecting partial defects (i.e. missing fuel pins). However, the other radiation detectors offer little more than qualitative radiation detection and "item counting" by radiation spikes. The resolution and accuracy of these systems needs to be enhanced, at least at new fast reactors, to better distinguish fresh TRU, DU blanket assemblies and low burn-up spent TRU fuel assemblies. This issue becomes more pressing when the various fuel assemblies can travel along the same pathway (i.e. removal of a fresh TRU fuel assembly as a "non-fuel" dummy used for periodically mechanically testing the equipment).

\footnotetext{
${ }^{3}$ Los Alamos National Laboratory (LANL) was in the process of upgrading the NDA systems at Monju to a progressive Modular Remote Monitoring "MRM" architecture as described in the noted reference.
} 
Table 3-1: NDA and Surveillance Systems at Monju ${ }^{20,21}$

\begin{tabular}{|c|c|c|c|}
\hline $\begin{array}{l}\text { Equipment } \\
\text { Abbreviation }\end{array}$ & $\begin{array}{l}\text { Equipment Name } \\
\text { (Quantity) }\end{array}$ & Remarks & $\begin{array}{l}\text { Provider of } \\
\text { Equipment }\end{array}$ \\
\hline ENGM & $\begin{array}{l}\text { Entrance Gate Monitor } \\
\text { (2) }\end{array}$ & $\begin{array}{l}\text { Monitors fresh TRU-fuel removed from } \\
\text { fresh fuel storage room. Coincident } \\
\text { neutron detector/analyzer. Capable of } \mathrm{Pu} \\
\text { verification for partial defects. }\end{array}$ & IAEA \\
\hline EVRM & $\begin{array}{l}\text { Ex-Vessel Radiation } \\
\text { Monitor (2) }\end{array}$ & $\begin{array}{l}\text { Monitors fresh and spent TRU-fuel } \\
\text { handling by the ex-vessel transfer } \\
\text { machine. Coincident neutron } \\
\text { counter/analyzer, ion fission chamber, and } \\
\text { gross gamma detector. }\end{array}$ & PNC (JAEA) $)^{4}$ \\
\hline EXGM & Exit Gate Monitor (1) & $\begin{array}{l}\text { Monitors spent TRU-fuel transfers from } \\
\text { the spent fuel canning station into the } \\
\text { spent fuel pond. Coincident neutron } \\
\text { counter/analyzer and ion fission chamber. }\end{array}$ & $\mathrm{JSGO}^{5}$ \\
\hline EVST & $\begin{array}{l}\text { Ex-Vessel Storage } \\
\text { Tank Monitor (2) }\end{array}$ & $\begin{array}{l}\text { Adjacent to Access Portals for Ex-Vessel } \\
\text { Fuel Storage Tank - monitors TRU fuel } \\
\text { transfers to and from the ex-vessel storage } \\
\text { tank. Coincident neutron counter/analyzer } \\
\text { and ion fission chamber. }\end{array}$ & IAEA \\
\hline RPM & $\begin{array}{l}\text { Reactor Core Power } \\
\text { Monitor (2) }\end{array}$ & $\begin{array}{l}\text { On Top of the Reactor Vessel - monitors } \\
\text { TRU-fuel transfers to and from the reactor } \\
\text { vessel and operation of the reactor. } \\
\text { Coincident neutron counter/analyzer and } \\
\text { ion fission chamber. }\end{array}$ & IAEA \\
\hline $\begin{array}{l}\text { VACOSS } \\
\text { SEALS }\end{array}$ & $\begin{array}{l}\text { VACOSS electronic } \\
\text { seals applied to fresh } \\
\text { fuel assembly storage } \\
\text { pits. (Several) }\end{array}$ & $\begin{array}{l}\text { In Fresh Fuel Storage Area and storage } \\
\text { pits in daisy-chain arrangement. Monitors } \\
\text { access to fresh TRU-fuel and removal } \\
\text { from storage pits. }\end{array}$ & IAEA \\
\hline DMOS & $\begin{array}{l}\text { Digital Multi-Camera } \\
\text { Optical Surveillance } \\
\text { (1 System, } 6 \text { Cameras) }\end{array}$ & $\begin{array}{l}\text { Cameras are situated throughout the } \\
\text { facility, often with redundant surveillance } \\
\text { coverage. Cameras are multiplexed to a } \\
\text { server located in the "Inspector's Room" } \\
\text { for downloading surveillance data. }\end{array}$ & IAEA \\
\hline DSOS & $\begin{array}{l}\text { Digital Single-Camera } \\
\text { (1) }\end{array}$ & $\begin{array}{l}\text { Viewing the Reactor core inside the } \\
\text { Containment. Monitors fuel movements in } \\
\text { the ex-vessel transfer machine to and from } \\
\text { the core, and possible ad hoc removal of } \\
\text { fresh TRU-fuel through the Containment } \\
\text { Personnel Air-lock. }\end{array}$ & IAEA \\
\hline
\end{tabular}

4 (Japan) Power Reactor and Nuclear Fuel Development Corporation "PNC", now known as the Japan Atomic Energy Agency "JAEA".

5 Japan Safeguards Office "JSGO", the national nuclear safeguards inspectorate in Japan. 
PNNL-17168

\section{Safeguards Approach Options}

\section{4.a Traditional Monju Advanced Safeguards Approach}

The international safeguards approach as presented in Section-3 for Monju is what could be expected for a new fast reactor coming under IAEA safeguards. Even though Monju uses advanced NDA and containment/surveillance measures, there are additional options, some of which will also be addressed in Section-7 "Novel Safeguards Approaches Possibilities".

As is the case for most of the fast reactors, the principle means of accounting for the nuclear material is in the form of integral items, i.e. complete fuel assemblies. However, historically, active well coincident counters, together with high-resolution gamma spectroscopy have been used to determine the U-235 and Pu content in TRU-fuel and then, by deduction based on enrichment, the total uranium content in the fuel. This safeguards verification has achieved accuracy of approximately $+/-4 \%$ in fresh TRU fuel. ${ }^{22}$ When the fresh TRU fuel is put into the fresh fuel store, it is typically put under redundant containment surveillance, which normally consists of a combination of electronic seals and redundant surveillance cameras. If properly arranged, the video surveillance cameras can cover the access doors to the fresh fuel store, as well as the sealed fuel storage pits themselves. If the fresh fuel is received in fresh fuel casks sealed with electronic seals, it may be possible to unload the cask in view of the surveillance cameras to ensure that all of the fresh fuel is put into storage (i.e. none has been removed) and the operator can apply VACOSS electronic seals that will record the date and time that the fuel has been put under seal. When the fresh fuel store is inspected by the IAEA, the video surveillance and electronic seal data will be down-loaded and the date and times of fuel handling will be confirmed and corroborated.

Fresh fuel is transferred to the fast reactor core typically by special fuel handling equipment (the ex-vessel transfer machine at Monju). It may be placed in an intermediate holding area, such as the ex-vessel storage tank for conditioning in liquid sodium, prior to be charged to the reactor core by the reactor fuel handling machine. All of the various points at which fresh TRU fuel could be removed are typically monitored by redundant video surveillance systems. At Monju the surveillance systems are complemented by redundant non-destructive assay systems to detect the presence of, and distinguish between dummy, DU blanket, fresh TRU-fuel and spent TRU-fuel at various stages in the fuel transfer path. These same systems are used to verify the transfer of spent fuel from the reactor core along the path to the spent fuel storage pond.

The spent fuel storage pond itself is normally under redundant video surveillance. In the case of Monju a non-destructive assay system is used to detect or confirm the movement of dummy, or spent DU-blanket or spent TRU-fuel to the spent fuel pond. The surveillance is used to not only confirm the arrival of spent fuel assemblies to the spent fuel pond, but also the removal of any spent fuel assemblies from the pond.

These safeguards activities are normally monitored by unattended surveillance and nondestructive assay systems that are typically down-loaded monthly by the visiting 
inspectors. The data from these systems will often be evaluated at the facility, or at a regional office (such as in Japan), or at IAEA headquarters in Vienna. In addition to the collection of the safeguards verification data by the unattended systems, the inspectors will review the nuclear material operating and accounting records at the facility for consistency with the verification data, i.e. to confirm receipts, shipments, and internal transfers of nuclear fuel. This comparison of operating records is further extended to comparison with the state reports as submitted by the national authorities to the IAEA. This then constitutes a consistency check of the nuclear material accounting records between the facility operator and as submitted by the national authorities.

This then is the current "state of the art" advanced safeguards approach as applied to the modern fast reactor Monju by the IAEA in Japan.

\section{4.b Remote Monitoring ${ }^{23}$}

However, changes in the safeguards approach are being made at Monju to remotely monitor more the unattended systems. In this case, the principle is that the digital NDA, surveillance, and electronic seal data would be collected at centralized data collection servers, which would be encrypted and periodically uploaded to secured servers in the IAEA regional office in Tokyo. The encrypted data collected on these servers would in turn be periodically transferred to secured servers at IAEA headquarters in Vienna. The benefit of such a "remote monitoring" scheme is that it would permit a remote verification of the safeguards data form either the Tokyo Regional Office or IAEA HQ. ${ }^{6}$ If such a scheme is properly implemented with adequate data encryption to address the concerns of the facility operator and national authorities, then it should be possible to reduce the frequency of on-site inspection from an average of once per month to once per quarter - since it could be confirmed that the un-irradiated fresh fuel was (or was not) under successful redundant containment/surveillance within the one month IAEA timeliness goal for detecting a diversion of fresh TRU-fuel. If there were discrepancies or apparent anomalies with safeguards data collected remotely, then it should be possible to dispatch an inspection team at relatively short notice to determine the status of the safeguards equipment or of the nuclear fuel at the facility. Because remote monitoring has shown the promise of both improving the effectiveness and efficiency of nuclear material safeguards, it is a very attractive option for safeguarding new fast reactors. However, remote monitoring will only be effective if the fundamental NDA, video surveillance, and electronic sealing systems are properly designed, installed, and integrated. Also, the data authentication and encryption systems and data collection and transmission software architecture must be robustly engineered.

Other options regarding advanced safeguards approaches, such as the use of shortnotice random inspections "SNRI" and the use of national and regional inspection authorities to support the inspection effort will be addressed in Section-7, "Novel Safeguards Approaches - Possibilities".

\footnotetext{
${ }^{6}$ Such a remote monitoring scheme is currently being implemented under the bilateral cooperation agreement between U.S. DOE and JAEA, Action Sheet 2, as funded by JAEA. Under this task, all Monju NDA, electronic seal and video surveillance data would be transmitted off-site once per day for remote collection by the IAEA. It is currently planned that this scheme would be completed in March of 2008 .
} 
PNNL-17168

\section{Safeguards Challenges}

\section{5.a Fresh Fuel of Varying Actinide Content}

The U-235, plutonium, and total uranium content can be determined in conventional fast reactor driver fuel, as has been demonstrated at many facilities handling plutoniumuranium mixed oxide (MOX) fuel, to the accuracy as noted in the IAEA International Target Values. This is typically on the order of $+/-7$ to $10 \%$ total Pu, or U-235. ${ }^{24} \mathrm{New}$ TRU-fuel for the ABR could also have elevated content of neptunium, americium, and curium, which would complicate the current assay for plutonium. This new TRU-fuel would therefore require new or modified methods of assay. In fact, it would be necessary for samples of such fresh TRU-fuel materials to be made available, so that the assay methods could be proven, at least in principle.

Such NDA systems typically depend on the geometry of the fuel, as well as perhaps the assay location in the facility. Consequently, it will be necessary to mock-up or model the fuel geometry to greatest extent practical to prove the assay technique. Consideration should be given to trying to reduce assay interference from either neighboring assemblies, or shielding an otherwise high radiation background expected near assay stations in parts of the facility. The most pressing need is to develop and demonstrate a means of non-destructive assay of fresh TRU-fuel that could detect "partial defects", i.e. have accuracy on the order of $+/-5 \%$ total Pu and actinides. Even though this level of measurement accuracy has been demonstrated with fresh HEU and MOX-fuel, the assay becomes more challenging when the fuel has elevated content of neptunium, americium, and curium. This is ultimately one of the most important areas of development need, because of the variable actinide compositions of TRU-fuels being considered, and because of the tendency of these minor actinides to complicate the assay of the fuel by coincident neutron counting.

\section{5.b Fully Integrated Collection and Review of Safeguards Data}

One of the greatest current challenges in safeguarding a fast reactor such as Monju is designing the safeguards systems into one integrated system or later integrating these independent systems for coordinated and centralized data collection. The typical systems for applying modern international safeguards at such a facility are as shown in Figure 31. Even though the advanced safeguards approach at Monju has demonstrated the effectiveness of unattended safeguards data collection, the fully integrated collection of such data has not yet been demonstrated. The data must be manually down-loaded from many of these unattended stations typically monthly. This NDA, surveillance and electronic seal data must be evaluated later, and by individual systems to determine whether there were any anomalies involving the TRU-fuel. It is true that the current review system allows for some correlating of data between some surveillance systems and NDA radiation detectors, but not to the fullest extent. Therefore, in a safeguards approach for future fast reactors, two additional development needs are the design and development of a fully integrated safeguards data collection system and the codevelopment of an integrated safeguards data review system that would be capable of handling the very large amounts of safeguards data from such an integrated system. As long as the review of this data remains largely dependent upon individual safeguards 
inspectors to load the data and perform the machine-assisted review of the data, this will be a weak link in the safeguards evaluation. This is not a trivial or necessarily straightforward problem, since an integrated safeguards data collection system will depend greatly on the design of the facility, which will necessarily vary because of the uniqueness of the design of fast reactors. However, as fast reactors become more commercially viable, it is expected that such centralized safeguards data collection systems will become standardized, like the reactor operating and control instrumentation.

Next is the need to develop a fully integrated suite of non-destructive assay monitors, surveillance, and electronic sealing systems. Such a system ideally would not be cobbled together, but would be a designed system of singular safeguards purpose. However, it could be constructed of commercial off-the shelf components and modules proven heretofore for nuclear material safeguards. The main feature is that the system should provide for centralized safeguards data collection. Secondly, it should at least in principle be possible to transmit the safeguards data remotely, to facilitate "remote monitoring" of the fast reactor, if adequate provisions are made to encrypt and protect sensitive data. Thirdly, is the related need to develop an integrated review system that would be highly automated and permit the collective review of all of the relevant safeguards data collected - i.e. a combined review of the digital video surveillance, nondestructive assay, and electronic seal data, correlated in time. Only with such a review system would it be possible to draw meaningful safeguards conclusions from such a large amount of digital data from such a broad array of safeguards instruments.

\section{5.c Verification of Spent TRU-Fuel}

Although redundant surveillance has been effectively used to detect the possible removal of spent fuel assemblies from the spent fuel pond, the current means of non-destructive assay (by the Exit Gate Monitor "EXGM") is not sufficiently accurate to assay the spent TRU assemblies for "partial defects" - i.e. the removal of spent fuel pins. This causes significant safeguards concern if the fuel can be dismantled in the spent fuel pond to remove and replace damaged pins. With many existing fast reactor fuel designs, this is not possible, but if fast reactor fuel design follows the trends of commercial LWR fuel, this then might be possible. For this reason, a non-destructive assay station such as the exit gate monitor would need to have sufficient accuracy to measure the content of $\mathrm{Pu}$ and actinides in the spent fuel on the order of $+/-5 \%$ total $\mathrm{Pu}$ and actinides. The issue of varying actinide content in the case of the spent fuel will complicate this challenge, since the current method using coincident neutron assay depends on assumptions that will not hold in fuel of highly variable curium content. Because of this, there is a need to optimize an NDA method for determining the Pu and actinide content of spent TRU-fuel, having the kind of composition that is expected in the range of future TRU-fuel designs. Another possibility is to ensure that the new fast reactor fuel cannot be easily dismantled in a spent fuel pond for pin removal. If the NDA technique is to be optimized for spent fuel, then the support of other countries with spent TRU-fuel of varying composition, such as the France, Russia, and Japan, may need to be enlisted - as they may have or 
could generate stocks of spent TRU-fuel for testing purposes that the U.S. does not currently possess. ${ }^{7}$

\section{5.d Distributed vs. Collocated Facilities}

Most nuclear fuel cycle facilities have historically been distributed. That is, the fuel fabrication, nuclear power reactor and nuclear fuel reprocessing facilities have been located at different sites. Although this was not always the case, it was generally so. The main reason was that there was no apparent advantage for such facilities to be collocated on the same site. The economic advantage was derived from scaling up the capacity of the facilities to derive a "greater economy of scale". So, nuclear power plants were grouped in modular clusters of 2 to 6 units (or 10, if one were to combine the Fukushima Dai-Ichi and Dai-Ni reactor groups in Japan), and fuel fabrication and reprocessing plants were doubled or tripled in capacity with the addition of other units. However, it must be remembered that the Integrated Fuel Cycle facility complex at the Idaho National Laboratory (formerly Argonne-West), which includes EBR-II and the collocated pyro fuel reprocessing and metallic fuel fabrication line demonstrated this concept of "collocation" 40 years ago. The idea was that the fuel from a fast reactor could be pyroprocessed in a suite of hot-cells adjacent to the reactor building to remove the neutronpoisoning fission products, and that this plutonium-bearing metal could be recast into new fuel rods in the hot-cell for reloading the fast reactor. The idea was and remains simple, elegant and ingenious. The fast reactor produced additional nuclear fuel during operation, the neutron-poisoning fission products that accumulated were removed by the pyro-processing, and the partly decontaminated fuel material was recycled - without regular receipts or shipments of plutonium or high-enriched uranium (HEU) fresh or spent fuel. Under the transmutation fuel cycle scheme being considered, the fast reactor may be an "actinide burner" rather than a "breeder", but the benefits of collocating fuel cycle facilities are the same - collocation reduces the risk of special fissionable material being intercepted and diverted either during shipment to, or from the nuclear power plant. Certainly, safeguarding collocated facilities is a degree simpler, because it is easier to monitor for the "borrowing" of nuclear material between facilities at the time of taking the physical inventory. This is more challenging if the nuclear facilities that ship and receive similar nuclear materials are distributed over the country. Nonetheless, safeguarding distributed nuclear facilities is a challenge that the IAEA and U.S. DOE have addressed for nearly forty years. In the end, it would seem that the decision regarding the collocation of nuclear facilities will be dictated based on the maturity of the facility design and the relative economics of distributed vs. collocated facilities. As a final word on this issue, it is worth noting that Toshiba Ltd. in Japan fairly recently prepared designs and an engineering model of next generation fast reactors, collocated with pyro-reprocessing, fuel fabrication and port facilities. ${ }^{25}$

There is a need to study the relative economic and reduced nuclear material diversion risk of collocated versus distributed fuel cycle facilities, especially for the new fast reactor, fuel reprocessing, and TRU-fuel fabrication facilities being considered (i.e. the ABR and $\mathrm{AFCF}$ ). At this stage of conceptual design, the demonstration facilities could be located

\footnotetext{
${ }^{7}$ Material accountancy issues at the pyro plant accentuate the importance of verification of the spent fuel assemblies before reprocessing.
} 
separately, but it is worth revisiting this issue, when considering the deployment of other such facilities.

\section{5.e Design Information Verification (for Safeguards)}

Under the safeguards agreement concluded between the IAEA and a member state, such as the United States, it is required that information regarding the planning, design, and construction of nuclear facilities be provided to the IAEA. ${ }^{26}$ As one of the safeguards measures developed to strengthen IAEA Safeguards in the early 1990s, the IAEA Board of Governors resolved that this nuclear facility design information should be provided to the IAEA as soon as the decision is made by the country to construct the facility, i.e. at the earliest opportunity. ${ }^{27}$

The IAEA performs periodic Design Information Verification "DIV" activities to ensure that the nuclear material removal paths are well defined and that the facility is being constructed in accordance with the facility operator's and state's declaration. Current policy anticipates that that new fuel facilities referenced in this report that are to be built in the United States would be on the Eligible Facility List (EFL) for possible random selection by the IAEA for actual safeguards inspection.

\section{5.f Alternative Nuclear Materials (ANM)}

Because Np-237 and Am-241 fission, they are considered "alternative nuclear materials". However, this also implies they should be safeguarded as special nuclear materials. This decision has been made by U.S. DOE and materials bearing these elements are safeguarded under U.S. DOE safeguard regulations. This should put the DOE in a good position to respond effectively to any future change in IAEA policy with regard to safeguarding ANM. Americium and neptunium are not defined by the IAEA as safeguardable "nuclear material," although the IAEA has requested member states to provide information regarding this material voluntarily. Presently, this is not a great concern for the IAEA, since very few states possess or actively demonstrate fuel reprocessing technology - the only viable route to separating americium and neptunium in significant quantities.

\section{5.g Equipment for Safeguards}

Equipment that will be offered to the IAEA for safeguards use must meet the IAEA's authentication requirements. These requirements have become more stringent in the recent past; so many equipment designers are not familiar with designing to these new standards. Also, future safeguards equipment should be designed to be more easily inspected for authentication purposes. The IAEA's equipment authentication procedures sometimes result in the expensive replacement of equipment. The ability to remotely ascertain the state of health $(\mathrm{SoH})$ of safeguards equipment and to perform remote maintenance on the equipment could greatly reduce the cost of operating the equipment while enhancing its reliability. Unfortunately, doing this without compromising the security of the equipment is extremely difficult and requires additional development. Enhanced tools for verifying facility design information for nuclear facilities is necessary throughout the lifecycle of the facilities. The 3-Dimensional Laser Range Finder Detector (3DLRF) was developed by JRC/Ispra and used extensively at RRP to verify the 
construction and installation of the main process cells, vessels, and piping of safeguards significance. ${ }^{28}$ However, these tools may need other features such as gamma detection and spectroscopy to permit the inspectors to verify the configuration of equipment and vessels in areas that that will no longer be accessible due to high levels or radiation or contamination. $^{29}$ In addition, there is a need to define a protocol for collecting and storing the design information verification "DIV" data. Such a protocol was established with JSGO in Japan with the detailed computerized topographic data collected by the 3DLRF. However, this was a very limited and unique case. Such a protocol would need to be established between U.S. DOE and the IAEA regarding the collection and storage of DIV data from a new fast reactor, such as the ABR as well.

As was noted in this report in Table 3-1, some of the NDA systems for Monju were actually purchased and provided by the plant operator (PNC/JNC/JAEA) and the national safeguards inspectorate (JSGO). Currently, IAEA Safeguards Department policy SGTS \#20 is fairly restrictive regarding the prospective sharing of equipment that provides safeguards data between the IAEA and another party. This has caused significant issues between the plant operator, national inspectorate and IAEA during the start-up of the Rokkasho Reprocessing Plant "RRP". Consequently, there is a need to involve the IAEA at an early stage to determine what data is ultimately required for safeguarding the new fast reactor and to determine who will provide what equipment, and to determine what data or equipment can be shared. It is also quite possible that the subject IAEA SG/SGTS Policy \#20 could be more flexibly interpreted - provided that the IAEA would still be able to gather enough safeguards data to derive independent safeguards conclusions regarding the facility. 


\section{Novel Safeguards Approaches - Longer-term Needs}

It should in principle be possible to apply an advanced safeguards approach similar to the one currently applied by the IAEA at Monju to a new fast reactor in the United States, such as the ABR. As was shown in Section-4, such an approach could be made more efficient and more effective using "remote monitoring" - provided that the facility operator and national authorities agree to the release of the safeguards data by remote transmission. Of course, such a scheme would need to involve encryption of the data and protection of sensitive and proprietary data.

\section{6.a Process Monitoring}

In addition to the ideas presented in Section- 4 are more novel ideas. The first pertains to the use of "Process Monitoring" - or in other words, more complete use of the facility operator's process instruments as an additional safeguards measure to ensure that the facility is being operated as declared. The safeguards approach at a fast reactor focuses primarily on the TRU-fuel, where it is stored, and the transfer pathways. Unlike the case of safeguarding a reprocessing or fuel fabrication facility, the process instruments in the case of a fast reactor are of relatively lesser safeguards importance. However, these instruments would still indicate whether the reactor is operating or not and consequently would still provide valuable additional information regarding the "declared operating status" of the facility. This is relevant when the safeguards question is raised regarding the quantity of plutonium or other actinides which could have been produced during the declared operating period, relative to the operator's declaration. So, there is still an argument to use the operator's instruments as an additional safeguards measure to support safeguarding a new fast reactor.

To use the operator's instruments effectively, there would have to be close coordination with the IAEA, especially regarding the Safeguard's Department/SGTS Policy \#20, concerning the joint use of equipment for safeguards purposes. The challenges ultimately become: determining what instruments can be shared, determining what data can be shared and how it can be shared, and finally integrating this data into the centralized safeguards data control and evaluation computer. Additionally, this data could be potentially reviewed by a predictive analytical model to confirm that the fast reactor is being operated as declared. With this knowledge, and with the safeguards data being transmitted and evaluated remotely, it should be possible to reduce the frequency of onsite inspection from monthly to once per quarter - which is still within the timeliness of detecting the diversion of spent TRU-fuel. This assumes that monthly evaluations of the safeguards data are done remotely and that the operator's declared fuel movements and number of stored TRU-assemblies are consistent with the data evaluated.

\section{6.b Randomized Inspection Approach}

The IAEA Safeguards Criteria defines the frequency of verification, and required level of detection probability, for the verification of plutonium and uranium, based on the type of nuclear facility, whether the material is "direct use", "non-direct use", irradiated, the type

of inventory, or inventory change, etc. ${ }^{30}$ However, if the safeguards approach were to use highly complementary safeguards measures, and if the facility operator could provide declarations of activities in advance, it is conceivable that the inspectors could perform 
more random inspections. These inspections could be Short Notice Random Inspections "SNRI". A fast reactor that has remotely monitored fuel assay, surveillance, and electronic sealing systems would be amenable to such a randomized inspection approach. However, it is still desirable for the inspection frequency to be on the average of once per quarter, considering the timeliness detection goal for the fresh and spent TRU-fuel. For this measure to be effective; the state would have to have acceptable "non-proliferation" credentials, the facility operator would have to have a history of being cooperative, the operator would have to be able to declare activities in advance, and the safeguards system would have to be capable of monitoring and recording the activities involving the TRU fuel.

\section{6.c Supplementing Inspection Effort with National or Regional Inspectorates}

There are cases where the IAEA has taken verification credit for safeguards verification activities performed by multi-national regional inspection agencies, such as Euratom and ABACC. ${ }^{31}$ Of course, this has depended on the type of inspection activity, and the IAEA has always insisted on the right to independently verify the activity. Another evolution of this idea could involve multi-national (regional) verification at a site level, for especially sensitive facilities, such as reprocessing, TRU-fuel fabrication plants, and fast reactors using TRU-fuel. There is already discussion of "International Fuel Cycle Centers" being subjected to international safeguards. ${ }^{32}$ However, what exactly this means and what it would entail is still being discussed. But along the same idea, a regional inspection agency could also inspect the "international" or "regional" fuel cycle facility, provided that they do this in support of the IAEA, and that the IAEA still has the right to perform independent verifications. In the case of the ABR what this could mean is that U.S.DOE or NNSA safeguards inspectors could perform safeguards inspections in alternating fashion with the IAEA, to supplement the IAEA's safeguarding of the facilities. If in the future there were a Pacific safeguards regional inspectorate, such as PACATOM (which could consist of states such as the U.S., Canada, Japan, Republic of Korea, and Australia), then the regional (PACATOM) inspectors could do safeguards inspections in support of the IAEA as is currently done by Euratom.

In summary, some novel safeguards concepts have been presented that go well beyond traditional safeguards measures and approaches. It is recommended that they be discussed in an international forum and in the most promising cases, that they be tested to determine if they do improve the effectiveness and efficiency of safeguards at a future fast reactor, such as the ABR. 


\section{Conclusions and Recommendations}

In looking at new fast reactors in light of the historical and reference facilities, the study concluded that an effective advanced safeguards approach could be developed based on safeguards measures currently employed at the Monju fast reactor. However, the team identified additional technical challenges and development "needs" for safeguarding the next generation fast reactors in general and the ABR in particular. Many of these needs are similar to those discussed in the two previous reports in this series that addressed advanced safeguards approaches for new reprocessing and TRU-fuel fabrication facilities, because the safeguards issues depend on the composition of the fresh and spent fuel, which is expected to be similar.

These needs are:

- Develop non-destructive assay (NDA) methods to accurately measure the plutonium $(\mathrm{Pu})$ and actinide content in fresh and spent TRU-fuel assemblies being received and shipped from the fast reactor. (This is currently complicated by the presence of other "minor actinides" and the high neutron and gamma radiation field of the spent fuel. These methods should be capable of detecting "partial defects in accordance with current IAEA criteria, i.e. having an accuracy of approximately $+/-5 \%$ total $\mathrm{Pu}$ and other actinides.) To demonstrate these methods, samples of the TRU materials planned for the future facilities will have to be prepared for testing purposes.

- Many of these NDA methods or systems will need to be designed "in-line" to measure the fresh fuel transfers to fuel storage and to the reactor core, and spent fuel transfers to spent fuel storage and from the reactor. These methods should be amenable to remote data transmission to permit "remote monitoring" of the facility for more efficient safeguards. Many of the NDA techniques are dependent on the geometry of the TRU-fuel and/or container. So, once the assay techniques are selected, the assay stations for the fresh and spent fuel will need to be "mockedup" to prove the techniques.

- Make greater use of automated, unattended/remote monitoring systems for collecting safeguards data, while cooperating with the facility owner/operator and national authorities to ensure protection of proprietary information. Develop a more completely automated and integrated safeguards data collect and review system for analyzing process and on-line assay data and surveillance imagery to support verification of the nuclear material transfers, inventory, and operational status of the facility.

- Establish an active dialogue with the IAEA to negotiate a more flexible interpretation of the IAEA Department of Safeguards SGTS Policy \#20, concerning the joint use of equipment for safeguards purposes. The current interpretation is very restrictive and limits the ability of the IAEA to use a broad range of existing plant instruments because of the supposed need to derive independent safeguards conclusions from these instruments. It is proposed that 
this strict interpretation should be applied only to those instruments of primary safeguards importance - and not to the extensive array of plant instruments, which could still provide complementary data of safeguards relevance regarding operation of the facility.

- Cooperate with the facility owner/operator and national authorities to try to design safeguards requirements and equipment into the conceptual design at the earliest stages of the conceptual design of the facility.

- Make the inspection regime more efficient by using randomized short-notice inspections, applying a "statistical process control" approach to verification of the reprocessing facilities rather than a scheduled systematic verification of all major transfers of plutonium-bearing materials. For this kind of approach to be effective the facility operator would need to declare the major activities involving nuclear material in advance. It would also be more efficient and effective to apply this approach on a site, rather than facility level.

- The current designs of new fast reactors, and the ABR in particular, are conceptual. To truly develop an optimized safeguards approach, the size and design of the new fast reactor would need to be better defined. At this level of conceptual review, the advanced safeguards approach can only be discussed in general terms.

- Current safeguards approaches for fast reactors depend strongly on the storage areas and transfer paths of the fresh and spent TRU-fuel. There is a need to review the current conceptual designs to see that such secure storage areas are designed into the process to facilitate stable process operation and to provide nuclear material inventory points that will facilitate nuclear material inventory stock taking.

If these needs are addressed, then the new fast reactors would be amenable to the application of international safeguards. 


\section{APPENDIX - A List of Acronyms and Abbreviations ${ }^{8}$}

93+2 - The "93+2" Campaign to strengthen safeguards at the IAEA, launched after the revelation of the clandestine nuclear weapons program in Iraq, circa 1991. It was launched in 1993 and was expected to take 2 years to define and implement a roadmap for strengthening IAEA safeguards. Several additional safeguards measure and new requirements came out of the program, which ultimately included those provisions and measures in the IAEA Additional Protocol.

ABR - Advanced Burner Reactor; a conceptual future fast reactor design considered under GNEP for actinide transmutation and commercial electrical power generation.

AFCF - Advanced Fuel Conditioning Facility; a conceptual research facility planned by the U.S. Department of Energy for the research and development of advanced nuclear fuel cycle technology. The facility is expected to conduct research over a period of 50 years in the area of proliferation-resistant nuclear fuel reprocessing and TRU-fuel fabrication.

ANM - Alternative Nuclear Material generally refers to TRU elements other than plutonium, such as neptunium and americium, which have fissile isotopes and which could also be used in nuclear fuel.

ASA-100 - Project under the United States Department of Energy NNSA Office of NA243, “Advanced Safeguards Approaches for New Nuclear Facilities, circa 2006 - 2007.

AWCC - Active Well Coincident Counter; a non-destructive assay instrument used to determine the plutonium and uranium content of fresh TRU-fuel using coincident-neutron counting and analysis. With a neutron source installed, the counter operates in an "active" mode to interrogate the nuclear fuel assembly by detecting the neutron induced fissions. With the source removed, the counter operates in a "passive mode" to detect the normal fissions from the fuel assembly. By comparing the passive to the active result, the counter can help determine plutonium, uranium and U-235 content.

$\mathbf{C} / \mathbf{S}$ - Containment and Surveillance; a term used by the IAEA to refer to safeguards measures that monitor nuclear material or equipment. Containment and surveillance measures include seals and tamper indicating devices and video surveillance cameras.

CFTC - Consolidated Fuel Treatment Center; a very large conceptual nuclear fuel reprocessing plant, planned by the U.S. Department of Energy, but which is expected to be designed, fabricated, and operated as a commercial fuel reprocessing plant. The current design is expected to process 3,000 tonnes of spent fuel per year, which would be nearly four times the size of current large-scale reprocessing plants. In principle, it would

\footnotetext{
${ }^{8}$ The definitions of acronyms and abbreviations are based on the references in the Reference Section of this report.
} 
be capable of reprocessing the entire amount of spent fuel generated annually by the current fleet of U.S. nuclear power plants. This conceptual facility was formerly called "ESD".

DMOS - Digital Multi-camera Optical Surveillance system; a standardized digital multiplexed video surveillance system used by the IAEA as a nuclear safeguards measure to monitor equipment and nuclear material.

DSOS - Digital Single-camera Optical Surveillance system; a standardized digital video surveillance system used by the IAEA as a nuclear safeguards measure that only has one camera.

DU - Depleted uranium; uranium with less than the naturally occurring amount of the fissile isotope, U-235 $(<0.7 \% \mathrm{U}-235)$. Depleted uranium is produced as "tails" a byproduct in a uranium enrichment plant. Commercially, there is very little use for depleted uranium, although this could change if "breeder" fast reactors became commercially viable, since they use reactor core "blankets" of depleted uranium.

EBR-II - Experimental Breeder Reactor-II; a former smaller scale experimental breeder reactor on the U.S. DOE Idaho Site.

EFL - U.S. Eligible Facility List; an extensive list of nuclear fuel cycle facilities in the United States provided annually to the IAEA under the U.S. Voluntary Offer Safeguard Agreement with the IAEA. Since the IAEA does not have the resources to inspect all of the nuclear fuel cycles in nuclear weapons states, such as the U.S., it randomly selects and rotates facilities for international safeguards inspection in nuclear weapons states.

ENGM - Entrance Gate Monitor; a radiation monitor at the fast reactor Monju that detects the transfer of fresh TRU-fuel during transfer from the fresh fuel storage area to the fresh fuel transfer machine.

EVRM - Ex-Vessel Radiation Monitor; two radiation monitors that sit adjacent to the two fuel transfer casks on the ex-vessel transfer machine to monitor whether there is fuel in the ex-vessel transfer machine, and for determining whether the fuel is dummy fuel, fresh TRU-fuel, DU blanket fuel, or spent TRU-fuel.

EVST - Ex-Vessel Storage Tank; an intermediate storage vessel at the fast reactor Monju for fresh assemblies being transferred to the core of the reactor for loading and for spent fuel assemblies being unloaded from the core for transfer to the spent fuel pond.

EVTM - Ex-Vessel Transfer Machine; a specially designed fuel handling machine at the fast reactor Monju that shuttles fresh fuel to the core of the reactor for loading and shuttles spent fuel being discharged from the core for transfer to the spent fuel pond. The ex-vessel transfer machine is monitored by redundant video surveillance to ensure that fresh or spent fuel is not removed. 
EXGM - Exit Gate Monitor; a radiation monitor at the fast reactor Monju that detects the transfer of spent fuel from the spent fuel form the spent fuel cleaning and canning area into the spent fuel pond.

FBR - Fast Breeder Reactor; a type of nuclear reactor that utilizes a "fast-neutron" spectrum. Such reactors are normally fueled with driver assemblies of highly-enriched uranium or plutonium. If such reactors use fertile nuclear material such as depleted uranium in the outer blanket of the core, they will actually produce more plutonium in the reactor by transmutation than they consume - hence the name "breeder". To be usable, the bred plutonium would have to be recovered by spent fuel reprocessing.

FFTF - Fast Flux Test Facility; a former large-scale experimental breeder reactor on the U.S. DOE Hanford Site, currently mothballed, which operated from 1980 to the 1990s.

GNEP - Global Nuclear Energy Partnership; a proposal by U. S. President Bush and the U. S. Department of Energy in 2005 to more fully develop nuclear energy worldwide for electrical power generation, while reducing the risk of the proliferation of nuclear weapons.

IAEA - International Atomic Energy Agency; an organization of the United Nations mandated to verify the compliance of countries (states) with their safeguards agreements regarding their nuclear material, in connection with the Treaty on the Non-Proliferation of Nuclear Weapons "NPT".

IIV - Interim Inventory Verification; a periodic safeguards inspection performed by the IAEA to verify that the nuclear material in the inspected nuclear facility has not been diverted and is being operated as declared. Historically, interim inspections for facilities handling plutonium have been performed monthly.

INL - The Idaho National Laboratory: one of the U.S. Department of Energy national laboratories that conducts research and development in nuclear fuel reprocessing, reactor design and nuclear waste management. This site is in eastern Idaho near the city of Idaho Falls. This site has formerly been called the Naval Reactor Testing Station "NRTS", the Idaho National Engineering Laboratory "INEL" and the Idaho National Environment Engineering Laboratory "INEEL".

JAEA - Japan Atomic Energy Agency (circa 2005 - present), also formerly (Japan) Power Reactor and Nuclear Fuel Development Corporation "PNC" (circa 1970s to mid 1990s) and the Japan Nuclear Fuel Cycle Institute "JNC" (circa mid 1990s to 2005). JAEA is a governmental-industrial concern in Japan with several large nuclear fuel-cycle facilities involved in the reprocessing of nuclear fuel, TRU-fuel fabrication and testing and operation of fast reactors. U.S. DOE has a bilateral cooperation agreement with JAEA in the area of advancing nuclear material safeguards.

JSGO - Japan Safeguards Office (circa mid 1990s to the present); the national authority in Japan mandated to monitor and verify compliance with domestic and international 
nuclear safety regulations and nuclear material safeguards requirements. JSGO is under the Japanese Ministry of Education, Culture, Science and Technology (abbreviated phonetically as "MEXT"). JSGO was formerly known also as the Japan Nuclear Safety Bureau (JNSB) and the Japan Atomic Energy Bureau (JAEB).

KMP - Key Measurement Point; a point in a nuclear facility where the nuclear material is measured for inventory or nuclear material flow. Key measurement points need to be defined for the IAEA to measure nuclear material inventory and flow in a facility subject to IAEA safeguards.

LWR - Light Water Reactor; a conventional nuclear reactor that uses normal "light" water for moderating and cooling the nuclear reactor core. Most commercial nuclear power plants in the world are light water reactors. Although light water reactors are well known and safe to operator, they do not breed plutonium to the extent as FBRs, or transmute actinides to the same extent burner reactors.

MBA - Material Balance Areas; areas defined in a nuclear facility for the purpose of nuclear material accounting. MBA's are used both by the U.S. DOE and the IAEA.

MOX - Mixed plutonium-uranium oxide. This is a variant of TRU-fuel material developed in the 1960s to the present for recycling plutonium from reprocessed nuclear fuel. MOX fuel programs had been active in the United States, Belgium, and Germany. They are still active in France, United Kingdom, Russia, Japan, and India. MOX-fuel fabrication technology is a forerunner of TRU-fuel fabrication, which in the future may also use neptunium, americium, and curium.

MUF - "Material Unaccounted For"; a term used in nuclear material accountancy (accountability) by the U.S. DOE and the IAEA that represents the difference between the beginning and ending inventory of nuclear material, after accounting for the inventory changes. The value of "MUF" is monitored closely, because it could indicate a possible theft or diversion of nuclear material - although proper statistical interpretation of the "MUF" is important to determine if the value is really statistical significant.

MWe - Megawatt, electric; a unit of electrical power output for any kind of electrical power generating station, expressed in term of millions of watts "megawatts". 1000 MWe is the rating of a typical large-scale commercial nuclear power station, which would be capable of powering a region like eastern Washington State.

MWth - Megawatt, thermal; a unit of thermal power output for any kind of power station, expressed in terms of millions of watts "megawatts". This is the total thermal power produced prior to the conversion to electrical power. For a power station of approximately $30 \%$ conversion efficiency, the thermal power output required would be nearly three times the electrical power produced. "MWth" is a more relevant unit of power output when discussing test and experimental fast reactors that do not have electrical power generators. 
NA-243 - The Office in NNSA responsible for nuclear material safeguards and nuclear non-proliferation issues in connection with International Treaties and Regimes.

NDA - Non-Destructive Assay: a means of analyzing nuclear material for the content of plutonium, uranium, and other elements and isotopes without destroying the sample. This technique is often preferred when handling highly radiotoxic elements such as plutonium, because the analysis can be performed with the nuclear material remaining secured in containers.

NNSA - The National Nuclear Security Administration: a separate administration under the U.S. Department of Energy dealing with nuclear security issues on a national level.

ORIGEN - a computer code developed to estimate the radionuclide content of spent fuel based on the original fuel composition, neutron exposure, fuel burn-up, and cooling time. The ORIGEN code has been extensively improved and adapted since it was originally developed, but still performs best for estimating the nuclide content of spent fuel from commercial light water reactors. It is typically used by nuclear reactor operators to estimate the content of plutonium, uranium, and U-235 in spent fuel for the purpose of nuclear material declaration.

PIT - Physical Inventory Taking; the physical verification and inventorying of all nuclear material in a facility (to the extent practical). Physical inventory verifications are typically conducted several times a year by the facility operator and national authorities. The IAEA typically conducts a physical inventory verification once per year at most nuclear facilities that they inspect.

Pu - The chemical symbol of plutonium.

RPM - Reactor Power Monitor: a radiation monitor at the fast reactor Monju that detects the transfer of fuel to and from the reactor core, and determines if the reactor is operating from the elevated radiation above the core.

SQ - Significant Quantity; in accordance with the IAEA and international experts, the amount of fissile material that would be required to make a simple fission "atom" bomb. Per definition this is $8 \mathrm{~kg}$ of plutonium and $25 \mathrm{~kg}$ of U-235 (in the form of highlyenriched uranium). The value of the significant quantity includes nuclear material that would be consumed or lost as waste in the various chemical and metallurgical processes in fabricating a nuclear weapon - i.e. it should not be construed to be the minimum amount of plutonium or highly enriched uranium required in a simple nuclear weapon.

TRU - Transuranic elements; typically those elements beyond uranium in the periodic table of the elements, including primarily plutonium, neptunium, americium, and curium. Many TRU isotopes are fissile and can be used as nuclear fuel, but most TRU elements are long-lived if left in radioactive waste and take hundreds of thousands of years to decay. 
TRU-fuel - Nuclear fuel consisting of uranium with transuranic elements such as plutonium, neptunium, americium, and curium.

U.S AEC - United States Atomic Energy Commission; the United States agency responsible for all nuclear facilities from circa 1945 to circa 1976.

U.S. DOE - United States Department of Energy; a cabinet-level department in the executive branch of the United States government with responsibility for former U.S. AEC nuclear facilities and the production and safeguarding of defense-related nuclear materials. Civilian nuclear facilities are regulated by the U.S. Nuclear Regulatory Commission "NRC". The U.S. DOE was created circa 1978.

U.S. ERDA - United States Energy Research and Development Administration; the United States agency responsible for nuclear facilities from circa 1976 to 1978. Under President Jimmy Carter the purview of this agency expanded beyond the development and testing of nuclear facilities and production of nuclear material to include research and development in other forms of energy as well.

VACOSS - A fiber optic based electro-optical sealing system used commonly by the IAEA. VACOSS seals record on-board data and document automatically the time and date that they are attached or detached. They can also be electronically interrogated and remotely monitored. Hence, they are becoming more important in sealing schemes replacing the old manually applied metal cap (or cup) seals. 
PNNL-17168

\section{References}

${ }^{1}$ U.S. Department of Energy "DOE” GNEP Web Site: "President Bush's Radio Address Focuses on Energy Issues," $<$ http://www.energy.gov/news/3222.htm>, February 18, 2006.

${ }^{2}$ U.S. Department of Energy "DOE" GNEP Web Site: "DOE Continues Path Forward on Global Nuclear Energy Partnership,"

$<$ http://www.gnep.energy.gov/gnepPublicInformation.html>, August 3, 2006.

${ }^{3}$ International Atomic Energy Agency: IAEA Safeguards Glossary, 2001 Edition, (Vienna, Austria: IAEA, 2002), p. 13.

${ }^{4}$ T. Deshimaru et al, (Japan) Power Reactor and Nuclear Fuel Development Corporation (PNC): "Safeguards in Prototype Fast Breeder Reactor Monju", International Atomic Energy Agency (IAEA) Symposium on International Safeguards, IAEA-SM-333, Vienna, March $14-18,1994$.

5 (Japan) Power Reactor and Nuclear Fuel Development Corporation (PNC), "Monju (Reactor Cutaway Diagram)", circa 1994.

${ }^{6}$ J. G. Yevick (editor): Fast Reactor Technology: Plant Design, MIT Press, 1966, pp. 714 and 715 .

7 Toshiba Ltd.: "Actinide Recycle Technology Development (brochure)" (bilingualJapanese and English), Toshiba Ltd., Kawasaki Works, August, 1995.

8 J. G. Yevick (ed.): Fast Reactor Technology: Plant Design, p.714.

${ }^{9}$ W. M. Gajewski et al., Hanford Engineering Development Laboratory "HEDL": "FFTF Companion Test and Development Facility for the LMFBR Program", U.S. AEC

Hanford Site, WHAN-SA-104 (revised), Richland, WA, March, 1971.

${ }^{10}$ U.S. Department of Energy (DOE) Web-Site, DOE Richland Operations Office: "Fast Flux Test Facility Facts", 2007.09.05.

${ }^{11}$ D. Spurgeon, U.S. Department of Energy (DOE): "Notice of Request for Expressions of Interest in an Advanced Burner Reactor to Support the Global Nuclear Energy Partnership", Washington, DC, July 31, 2006.

12 International Atomic Energy Agency: IAEA Safeguards Glossary, 2001 Edition.

${ }^{13}$ International Atomic Energy Agency (IAEA): "The Structure and Content of Agreements between the Agency and States Required in Connection with the Treaty on the Non-Proliferation of Nuclear Weapons", INFCIRC/153 (corrected), (IAEA, Vienna, Austria, 1972). 
${ }^{14}$ International Atomic Energy Agency: Safeguards Criteria, IAEA Department of Safeguards, 2004 Edition, Section-3, "Other Types of Reactors (FBR, ATR, and HTR)", and Annexes, Vienna, Austria, 2004.

${ }^{15}$ Rich Hooper: "Seminar on IAEA Strengthened Safeguards", Tokyo, Japan, 2001.

${ }^{16}$ International Atomic Energy Agency (IAEA): "Model Protocol Additional to the Agreement(s) between State(s) and the International Atomic Energy Agency for the Application of Safeguards", INFCIRC/540 (corrected), IAEA, Vienna, Austria, September, 1997.

${ }^{17}$ Japan Nuclear Fuel Cycle Institute (JNC): "Monju Safeguards Equipment”, JNC Tsuruga Office, Japan, circa 2004.

${ }^{18}$ P. C. Durst: private communication regarding FBR Monju, August, 2007.

${ }^{19}$ D. H. Beddingfield and T. J. Digby: "Monju Remote Monitoring System (Phase II)", Los Alamos National Laboratory (LANL), September, 2004.

${ }^{20}$ D. H. Beddingfield et al.: "Monju Remote Monitoring System (Phase II)", September, 2004.

${ }^{21}$ T. Deshimaru et al., (PNC): "Safeguards in Prototype Fast Breeder Reactor (Monju)", Vienna, March $14-18,1994$.

${ }^{22}$ H. Aigner et al, International Atomic Energy Agency (IAEA): "International Target Values 2000 - for Measurement Uncertainties in Safeguarding Nuclear Materials", STR327, Vienna, Austria, 2001.

${ }^{23}$ D. H. Beddingfield et al.: "Monju Remote Monitoring System (Phase II)", September, 2004.

${ }^{24}$ H. Aigner et al.: "International Target Values 2000”, IAEA, 2001.

${ }^{25}$ Toshiba Ltd.: “Actinide Recycle Technology Development,” August, 1995.

${ }^{26}$ IAEA: INCIRC/153 (corrected), Vienna, Austria, 1972.

${ }^{27}$ Rich Hooper: "IAEA Strengthened Safeguards Seminar”, Tokyo, Japan, 2001.

${ }^{28}$ V. Sequeira, G. Boström, M. Fiocco, D. Puig, J. and G.M. Gonçalves of the European Joint Research Center at Ispra, Italy: "3D Site Modeling and Verification of Plant Design for Nuclear Security Applications", Proceedings of the 2005 IEEE Computer Society Conference on Computer Vision and Pattern Recognition (CVPR'05), San Diego, CA, June 20-25, 2005. 
${ }^{29}$ L. Mihailescu: "A 3D Gamma Information Verification Scanner (3D-GIVS) for Inspection and Characterization of Nuclear Materials," Lawrence Livermore National Laboratory, Livermore, CA, draft circa June, 2007.

${ }^{30}$ International Atomic Energy Agency: Safeguards Criteria, Section-3, Vienna, Austria, 2004.

${ }^{31}$ S. Thorstensen and K. Chitumbo: "Increased Co-operation between IAEA and Euratom: The New Partnership Approach," IAEA Symposium Proceedings, International Nuclear Safeguards, 1994, p. 271-283.

${ }^{32}$ Rosatom: "International Uranium Enrichment Center," (English translation from Russian), October, 2006. 